\title{
NBSIR 86-3442
}

Al1102 ᄂ1646?

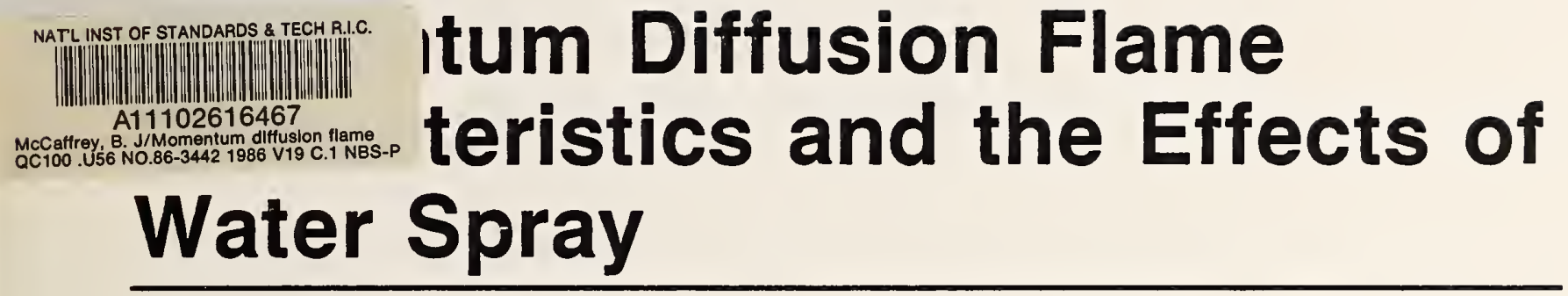

B. J. McCaffrey

U.S. DEPARTMENT OF COMMERCE

National Bureau of Standards

National Engineering Laboratory

Center for Fire Research

Gaithersburg, MD 20899

November 1986

Sponsored by:

nonartment of the Interior - $A C$ r rals Management Service on, VA 

NBSIR 86-3442

MOMENTUM DIFFUSION FLAME
CHARACTERISTICS AND THE EFFECTS OF
WATER SPRAY

B. J. McCaffrey

\section{U.S. DEPARTMENT OF COMMERCE}

National Bureau of Standards

National Engineering Laboratory

Center for Fire Research

Gaithersburg, MD 20899

November 1986

Sponsored by:

Department of the Interior

Minerals Management Service

Reston, VA

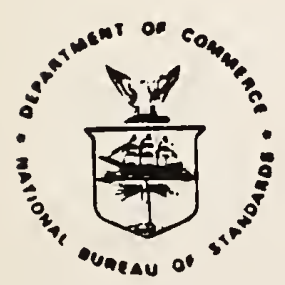

U.S. DEPARTMENT OF COMMERCE, Malcolm Baldrige, Secretary NATIONAL BUREAU OF STANDARDS. Emest Ambler, Director 

List of Figures $\ldots \ldots \ldots \ldots \ldots \ldots \ldots \ldots \ldots \ldots \ldots \ldots \ldots \ldots \ldots \ldots \ldots \ldots \ldots \ldots$

Abstract $\ldots \ldots \ldots \ldots \ldots \ldots \ldots \ldots \ldots \ldots \ldots \ldots \ldots \ldots \ldots \ldots \ldots \ldots \ldots \ldots \ldots \ldots \ldots \ldots$

1. INTRODUCTION $\ldots \ldots \ldots \ldots \ldots \ldots \ldots \ldots \ldots \ldots \ldots \ldots \ldots \ldots \ldots \ldots \ldots \ldots \ldots \ldots \ldots \ldots \ldots$

2. EXPERIMENTAL .................................... 3

3. RESULTS AND DISCUSSIONS .......................... 5

3.1 Blowoff $\ldots \ldots \ldots \ldots \ldots \ldots \ldots \ldots \ldots \ldots \ldots \ldots \ldots \ldots \ldots \ldots \ldots \ldots \ldots \ldots \ldots \ldots \ldots \ldots$

3.2 Flame and Lift-Off Heights $\ldots \ldots \ldots \ldots \ldots \ldots \ldots \ldots \ldots \ldots \ldots \ldots \ldots \ldots . \ldots \ldots$

3.3 Flame Temperature ................................ 15

3.4 Radiation ....................................... 18

3.5 Effect of Water Spray .......................... 26

4. ACKNOWLEDGMENTS .................................. 42

5. REFERENCES ..................................... 43

6. NOMENCLATURE .................................... 45 
Figure 1. Schematic of experimental factlity ................. 47

Figure 2. Flame stability and blowoff characterization for methane.... 48

Figure 3. Flame and lift-off heights vs Froude number ............ 49

Figure 4. Present and literature summary of methane lift-off

height data $\ldots \ldots \ldots \ldots \ldots \ldots \ldots \ldots \ldots \ldots \ldots \ldots \ldots \ldots \ldots \ldots \ldots . \ldots \ldots$

Figure 5. Centerline temperature rise vs scaled helght ........... 51

Figure 6. Peak temperature vs nominal heat release rate (symbols follow Fig. 5) ................................ 52

Figure 7. Incident radiant flux to two targets as a function of fire size $\ldots \ldots \ldots \ldots \ldots \ldots \ldots \ldots \ldots \ldots \ldots \ldots \ldots \ldots \ldots \ldots \ldots \ldots \ldots \ldots \ldots \ldots \ldots$

Figure 8. Flame extinction coefficient and temperature for a fixed value of the other as a function of fire size ........ 54

Figure 9. Derived extinction coefficient (upper portion) using smoothed temperature data from Fig. 6 (lower portion) vs heat release rate $\ldots \ldots \ldots \ldots \ldots \ldots \ldots \ldots \ldots \ldots \ldots \ldots \ldots \ldots \ldots \ldots$

Figure 10. Sensitivity analysis of flame radiation model to

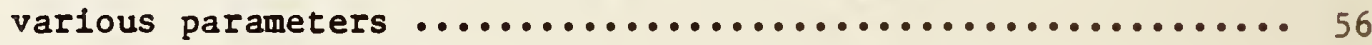

Figure 11. Predicted decreasing radiative fraction compared to literature data plotted as a function of the square root

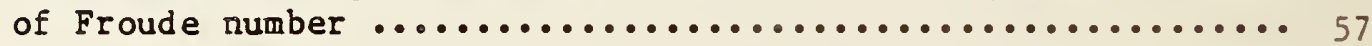

Figure 12. Centerline temperature rise vs helght with and without water spray $(Q=1.2$ and $2.3 \mathrm{MW}) \ldots \ldots \ldots \ldots \ldots \ldots \ldots \ldots \ldots$

Figure 13. Centerline temperature rise vs helght with and without

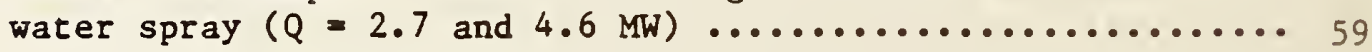

Figure 14. Reduction of peak temperature with water flow rate ........ 60

Figure 15. Fractional increase in lift-off helght due to water spray as a function of mass flow ratio ................ 61

Figure 16. Normalized incident flux and flame temperature reductions

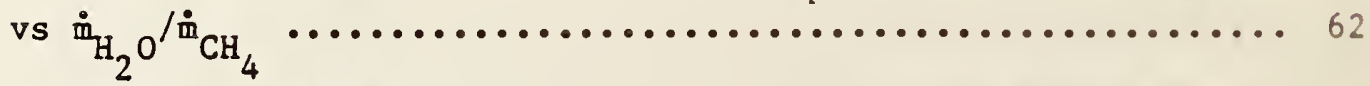

Figure 17. Increase in flame absorptivity as a function of both water flow rate and the difference between the heat flux and

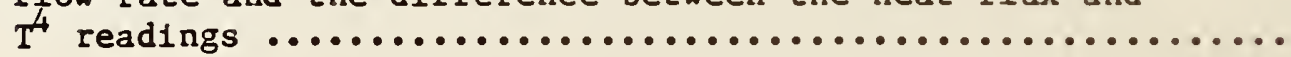


Figure 18. Water vapor emissivity and partial pressure plotted against the water to gas flow ratio ......................... 64

Figure 19. Derived entrainment rates vs predictions of Ricou and Spalding (1961) using effective source $\mathrm{pV}$ 



\section{Abstract}

For water spray suppression of gas well blow-out fire applications, reasonably large scale (1-10 MW) subsonic methane diffusion flames have been investigated near the high Froude number limit. Characteristics of this limit include constant flame height, increasing lift-off height, and decreasing radiative fraction. Flame blow-off has been observed with pipe sizes to $30 \mathrm{~mm}$ diameter. Flame and lift-off heights, centerline temperatures, and incident radiative flux to nearby targets have been measured with and without water spray suppressant. Using the Dayan-Tien formulation for a cylindrical flame model an effective gray absorption coefficient approaching $0.2 \mathrm{~m}^{-1}$ was determined at the blow-off limit. Away from the limit, this number rises rapidly as does flame temperature decrease. The derived shape of the functional dependence of decreasing radiative fraction with increasing jet Froude number in the limit is consistent with small scale literature. experiments.

The effect of adding water spray to the gas flow below the base of a lifted flame is to shift or raise the flame above its normal position, and to lower peak flame temperature and radiation levels despite increased absorptivity due to the radiatively active steam. Extinguishment near blowoff is thought to be due to the former effect, i.e., a shift in flame position. Calculations of flame entrainment based on increased water vapor emission are consistent with literature estimates of entrainment when account of the effects of buoyancy due to the liquid spray is provided.

Key words: blow-off, blowout fires, diffusion flames, entrainment, extinguishment, radiative fraction, suppression, water sprays. 


\section{INTRODUCTION}

Recent small scale studies (McCaffrey 1984) have demonstrated the efficacy of using limited quantities of water in the form of sprays to suppress and extinguish jet diffusion flames. Radiation reductions were equivalent to those obtained using premixed gaseous diluents, and extinguishment with mass flow rates of water approximately equal to that of the fuel was documented. Since part of that work was motivated by the desire to evaluate the feasibility of using water sprays to control and extinguish off-shore gas and oil well blow-out fires it is natural to inquire as to how far these small scale results could be extrapolated. The present work is an attempt not only to extend the size of the fire and determine any new scale-dependent phenomenon but also to increase the understanding of high velocity jet diffusion flames. In this regime, flame heights become dependent on burner diameter and the radiative fraction becomes dependent on gas flow rate. It is felt that this regime together with the very buoyant end of the Froude number scale, characteristic of the pool fire, contain more information about diffusion flame phenomena than is contained in the vast intermediate regime where all flames appear similar, 1.e., flame heights independent of burner slze and radiative fraction independent of flow (McCaffrey 1981).

The following describes an experimental program where large methane diffusion flames ( $7 \mathrm{MW}$ heat release rate and $7 \mathrm{~m}$ flame helght) were studied in an attempt to further extend the small scale findings about the effects of water spray on jet diffusion flames. 


\section{EXPERIMENTAL}

Figure 1 schematically depicts the experimental facility. The main working area is the floor of an abandoned missile pit located about 5 m below ground level. The flame is directed upward through opened silo doors somewhat protecting the lower flame region from wind disturbances. The floor area of the pit is sufficiently large and the whole space is in contact with an adjacent stair tower open to ambient so as to provide (quiescently) sufficient air for jet flame entrainment, i.e., air needn't be sucked down through the silo door opening.

Uncoated twenty-four gauge ( 0.5 mm diameter) chromel-alumel thermocouple wire was used for temperature measurements ( $11-T 6)$. Experience with smaller diameter wire in this very abrasive environment indicated that the penalty in terms of replacing thermocouples would be too severe for using finer gauge materials. Steel wire and connectors for thermocouple supports were required. Water cooled, wide angle, heat flux sensors ( $R 1 \& R 2$ ) were used for monitoring incident radiant heat flux at the positions indicated. Standard rotameters were used to measure water and the methane driver flow through the two-fluid atomizing nozzle. The main $\mathrm{CH}_{4}$ burner flow rate was measured using a laminar flow element mass flow rate device.

After reaching steady conditions at the operating point data channels for the temperatures, radiation, and $\mathrm{CH}_{4}$ flow rate were scanned sequentially five times and average values were determined for each data channel and used in subsequent analysis. 
In determining blowoff velocity as a function of outlet diameter various standard hardware items, pipe nipples and reducers, were used without further preparation. For the temperature and radiation measurements the largest of these, a $0.0292 \mathrm{mD}$ pipe reducer complete with internal threads, and the configuration seen in the highlighted ellipse on Fig. I were used. The latter consisted of a $0.0318 \mathrm{mD}$ circular hole cut straight through (as contrasted to a sharp edged orifice, for example) a $.008 \mathrm{~m}$ thick cap on the end of a $0.104 \mathrm{mD}$ pipe which contained the spray nozzle. The top of the nozzle was located $0.059 \mathrm{~m}$ from the top of the opening.

The nozzle was a two fluid or pneumatic atomizing nozzle, $1 / 2 \mathrm{~J}$ designation from Spraying Systems Co.* Methane gas from a separate supply served as the pneumatic atomizing fluid operating around $150 \mathrm{kPa}$. The flow of methane was added to the main gas when calculating heat release rates, etc. It constituted a small fraction of the total. The pneumatic nozzle was chosen to provide relatively small water drops which it was hoped would optimize the process of getting the drops into the combustion gases. Other methods of spraying water at the flame, e.g., an external spray, might be compared to this more idealized configuration. Differences may be then computed in terms of a delivery efficiency.

*Implies no endorsement by NBS. 


\section{RESULTS AND DISCUSSIONS}

\subsection{Blow-off}

An interesting and significant feature of jet diffusion flames, generally not encountered in smaller laboratories, involves blow-off and the concept of absolute flame stability. When the flow rate of gas being supplied to a small diameter pipe or burner, upon which is attached a free vertical jet diffusion flame, is increased, the flame begins to separate from or to "exist" a small distance above the exit of the burner. As the flow rate is further increased this lift-off distance becomes larger until with further increase in flow rate a point is reached - blow-off, whereby a flame cannot be sustained for that particular gas burning in that particular geometric configuration. For a variety of hydrocarbon gases and mixtures rather extensive compilations of blow-off data have recently appeared (Kalghatgi 1981, 1982).

Kalghatgi's data answers the question of what fuel flow rate expressed as the exit gas velocity just causes the flame from a given sized burner to blowoff. Kalghatgi (1981) was able to correlate all his data in terms of a nondimensional blow-off velocity, $\bar{U}_{e}$ as a function of Reynolds number, $R_{H}$, based on a characteristic lift-off distance, $H_{S}$, which in turn depends on an effective burner diameter. Both $\bar{U}_{e}$ and $R_{H}$ contain $S_{u}$, the maximum laminar flame speed, which accommodates the data from such gases as diverse in their burning velocity characteristic as hydrogen and methane. Figure 2 presents the results of the correlation in terms of dimensional velocity at blowoff versus actual pipe diameter for methane gas both for a low and a high range of $\mathrm{R}_{\mathrm{H}}$ (solid and dashed curves). Note from the equations shown on the figure for 
both ranges of $R_{H}$, the velocity-Reynolds number (or diameter) relation appears to be linear and, in fact, the solid curve for the lower velocities, smaller diameters $\left(R_{H}<30,000\right)$ is indeed linear. The interesting phenomenon however takes place at larger diameters, higher flowrates where compressibility effects associated with choked flow and underexpanded jet behavior begin to dominate. The near linear relationship in non-dimensional space exhibits the "doubling back" behavior in dimensional space.

When the gas flowrate through a pipe, hole or other aperature not specifically designed with supersonic effects in mind is increased to sonic conditions at the exit plane the pressure there will generally be higher than atmospheric and the flow will have to expand in some form of a supersonic plume above the exit. In order to estimate the flow conditions in such a situation the pipe or burner exit is generally concelved to be replaced by a convergent-divergent nozzle having sonic conditions occur at the throat and at the exit of which the flow has expanded supersonically to atmospheric pressure. The relationship between this effective diameter, $d_{e}$, and the actual pipe or burner diameter, $d_{b}$, comes directly from standard 1sentropic flow equations and is:

$$
\frac{d_{e}}{d_{b}}=\frac{1}{\sqrt{M}}\left[\frac{2+(\gamma-1) M^{2}}{\gamma+1}\right]^{\frac{\gamma+1}{4(\gamma-1)}}
$$

where $M$ is the exit Mach number after expansion and $Y$ is the ratio of specific heats. The quantity $\mathrm{d}_{\mathrm{e}} / \mathrm{d}_{\mathrm{b}}$ is greater than one and increases monotonically with M. In order to observe the behavior of the dashed line on F1g. 2 we simply solve the inverse problem, $1 . e .$, find $d_{b}$ as a function of $U_{e}$. It can be shown that for linear or near linear $\bar{U}_{e}=f\left(R_{H}\right)$, that is, $U_{e}$ almost linear 
with $d_{e}, d_{b}$ is basically equal to $M$ or $U_{e}$ divided by $d_{e} / d_{b}$, and the quantity $\frac{M}{d_{e} / d_{b}}$ goes through a maximum at about a Mach number of 2, thereafter the ratio falls in magnitude, i.e., the effective diameter is growing more rapidly with Mach number than simple proportionality•

The data used by Kalghatgi (1981) for which the curve on Fig. 2 is a correlation only extend out to pipe sizes of diameter equal to 12 for $\mathrm{CH}_{4}$. The turning back behavior noted near $40 \mathrm{~mm}$ and $\mathrm{M} \sim 2$ is therefore based on a significant extrapolation of that data. However, Annushkin and Sverdlov (1979) have given an analysis and some data for hydrogen which confirms the general shape of Fig. 2. That shape is extremely important since it demarks blowoff stability, exhiblting a dual significance. Firstly, for small to moderate size holes or cracks in pipes there is another stable regime where if the stagnation pressure is high enough diffusion flames can again be supported. They will be supersonic jet flames. This is for diameters where at low velocity the flames could easily be blown off if the velocity were increased up to the lower curve on Fig. 2. By further increasing the velocity or pressure we intersect the upper half of the stability envelope and presumably again can sustain a flame. Only for hydrogen has this been confirmed since it turns out that the critical diameter (the maxima of the $d_{b} v s U_{e}$ plot) for $\mathrm{H}_{2}$ is small and hence the experiments can be performed with a relatively small apparatus and modest quantities of hydrogen.

The second aspect to the stability curve on Fig. 2 is the existence of the critical diameter beyond which flames cannot be blown off for any flow, supersonic or subsonic. Seen on the figure by crosshatched vertical lines are two estimates of the critical diameter for methane gas - approximately $40 \mathrm{~mm}$, 
due to Kalghatgi (1981) from extrapolation of small diameter blowoff results; and approximately $25 \mathrm{~mm}$, from the analysis of Annushkin and Sverdlov (1979). No data exists at present to check these results because of the difficulties associated with producing and burning supersonic methane flows from orifices about $40 \mathrm{~mm}$ in diameter.

The present data shown by circles and sexagons are blow-off results of flames from gas flow through ordinary plumbing components - pipe nipples: relatively smooth sections of straight pipe or tube with a length to diameter ratio of about 2, and threaded reducers: converging sections of p1pe hardware ending in internal coarse, pipe thread. These would represent, at least for circular openings, a range of exit. flow conditions which might be encountered in practice. It is not evident from the figure that a significant difference exists between the results of the two exit configurations nor is it ev1dent why the present values are falling lower than Kalghatgi's (1981) extrapolation. Those results were for blow-off from straight tubes 65 m long and would represent somewhat different exit flow field conditions even for the largest of the methane results which was a diameter of $12 \mathrm{~mm}$.

What is evident from the figure is that the Annushkin and Sverdlov (1979) analytical findings will need to be modifled since their predicted diameter for absolute flame stability was exceeded by the last two data points, $26.2 \mathrm{~m}$ and $29.2 \mathrm{~mm}$. Also, if the trend of the present data persists with further experiments, i.e., continues to fall below and exhibits a gradually decreaslng slope compared to the small diameter extrapolation, then the estimate of critical diameter for $\mathrm{CH}_{4}$ must be increased. The absolute value at this juncture is not as important as the understanding of, or at least, some 
knowledge of blowoff and absolute flame stability. In subsequent studies of the suppression and extinguishment of large jet flames using water sprays the relative stability of the flame with regard to blow-off must be known in order to separate momentum effects of the spray (liquid drops plus entrained air) from purely thermodynamic ones. Are we in fact just "pushing off" a marginally stable flame at small diameters which at prototype scale could not be blown off so easily?

\subsection{Flame and Lift-Off Heights}

Figure 3 presents flame height (measured from pipe outlet) and lift-off height, both normalized by outlet diameter, as a function of source Froude number, $U^{2} / g D$. Shown with this $30 \mathrm{~mm}$ diameter data are various literature correlations. The vertical arrow indicates the position where blow-off occurred. The Froude number regime here is such that the flames are lifted, loud, and turbulent by most researchers' definition with a noticeable decreased luminosity as blowoff is approached. The pipe exit Reynolds number $(U D / \nu)$ ranges from 30,000 through 500,000 for the data points shown. For flame height, the break in the Suris, et al. (1977) correlation at a Froude number approximately equal to $3 \times 10^{4}$ is to mark the beginning of the Froude number independent regime for flame height. This recommended value is based on a considerable body of data. The transition value suggested by Becker and Liang $(1978)$ is quite a bit higher - orders of magnitude higher $\left(\xi_{L} \rightarrow 1\right.$ in their notation vs, about $\xi_{L}+8.6$. Froude number is inversely proportional to this number cubed, a Richardson number using flame height as the length scale). Their resulting flame height/diameter at the limit is about 420 vs. about 220 for the Suris et al. (1977) recommendation. The present three data 
points in this region could not differentiate or give support to either correlation seen on Fig. 3. To go beyond this data in Froude number however would require some $\mathrm{H}_{2}$ or $\mathrm{O}_{2}$ or other stabilizing gas to keep the flame from blowing off the end of the pipe. For the present, either representation is sufficient, although from a practical point of view, the Suris et al. (1977) result might be preferred for this subsonic case. There is probably more theoretical justification for the Becker \& Liang (1978) correlation but the classical $2 / 5$ Froude number power represented by the Suris et al. (1977) correlation is computationally easier. The dotted line shown on the figure prior to the limit is for methane,

$$
\mathrm{H}_{\mathrm{f}} / \mathrm{D}=28 \mathrm{Fr}^{0.2}
$$

For other fuels the numerical constant will vary with the square root of the density ratio, the simple manifestation of conservation of momentum.

Irrespective of which flame height representation is chosen the Important point here is that no scale effect is evident. That is, for pipe dlameters to $30 \mathrm{~mm}$ and velocities to blowoff, small scale laboratory flame height correlations do an adequate job in representing the large scale flame height data. Neither does the pipe exit configuration, i.e., flat-edged orffice or reducer, appear to make a difference in flame height.

The lift-off data, though scattered, rises more or less consistent with the literature prediction of lift-off height being proportional to gas velocity or here, a square root dependence upon Froude number, with blowoff coming near $L_{f} / D=50$. Peters and Williams (1983), using scalar dissipation arguments recommend the following: 


$$
\mathrm{L}_{\mathrm{f}} / \mathrm{D}=0.0036 \sqrt{\mathrm{g} / \mathrm{D}} \mathrm{Fr}^{1 / 2}
$$

with the numerical .0036 having units of seconds. Or

$$
\mathrm{L}_{\mathrm{f}} / \mathrm{U}=3.6 \mathrm{~ms}
$$

Note that $L_{f}$ is therefore independent of $D$. (The scaling on Fig. 3 for $L_{f}$ is permissible since all the data are for essentially a single diameter.) Kalghatg1 (1984) correlated lift-off data from a variety of fuels and pipe sizes to $10 \mathrm{~mm}$ in terms of dimensionless variables derived from his previous blowoff studies:

$$
L_{f}=C_{2} \frac{\nu}{s_{u}^{2}}\left(\frac{\rho_{e}}{\rho_{\infty}}\right)^{1.5} U
$$

with $C_{2}$ approximately equal to 50. Substituting kinematic viscosity and laminar flame speed appropriate to methane yields a constant equal to $0.0022 \mathrm{~s}$, somewhat less than the Peters and Williams (1983) value of .00365 . It is interesting to note that Kalghatgi's (1984) variables are based on the more conventional arguments involving the extinction point being near the absence of an appropriate stoichiometry for reaction or the inequality of gas flow velocity and turbulent burning flame speed as opposed to the flame stretching argument of Peters and Williams (1983). Both correlations are shown or Fig. 3.

The disagreement between the correlations for lift-off seen in the figure as well as the high degree of scatter in the data led to further study and an assembly of previous literature lift-off data. Figure 4 is the result. 
(There are far less experimental data available for lift-off helght compared to flame height.) What is critical for the present study is the determination of how well one can scale to very large fires. The appropriate parameter here is burner diameter and the object then, is to see how things vary with it. What is plotted is the average value of the constant referred to above, 1.e., the ratio of the lift-off distance to the exit gas velocity - the time for a gas parcel to travel from the burner exit to the bottom of the flame, as a function of diameter. For a given diameter the average of reported $L_{f} / U$ values is calculated and plotted on Fig. 4. High and low values are shown by the vertical lines on the symbols. The number of experiments for any average is shown by the number beside the symbol. Note that all of the data is for $\mathrm{CH}_{4} \cdot$

Contact can be made between the values of $\mathrm{L}_{f} / U$ quoted above and the previous figure and what one observes on Fig. 4. The open circles clustered around $2.4-2.5 \mathrm{~ms}$ represents the data of Kalghatg1 (1984). The 2.2 ms quoted above is derived from correlating all his data involving several different gases. Those gases will have lower $L_{f} / U$ values and weight the average lower. Observation of Fig. 3 indicates that this result falls below most of the present data points and the correlation due to that of Peters and Williams (1983). Their value, $3.6 \mathrm{~ms}$, has been determined from the open square symbols representing the data of Horch.

Based on Fig. 4 the question to ask is: 1s there a systematic dependence of $\mathrm{L}_{\mathrm{f}} / \mathrm{U}$ upon $\mathrm{D}$ ? The implication of such a dependence could be extremely important in trying to extrapolate lift-off data to larger scale. Like blowoff, lift-off is critical in attempting to understand diffusion flame stabil- 
ity, and therefore in trying to understand flame suppression and ultimate extinguishment with water sprays. Theoretical implications for the presence or absence of a $D$ dependence are quite significant. Within any particular group of points no dependence on $D$ is apparent, however, one might argue, especially if one included the filled or present results, that, in fact, some overall dependence might be present.

There is another relevant piece of work, not included in Fig. 4 involving propane flames from burner diameters 10 to $80 \mathrm{~mm}$, although the data from the larger D are for quite small Froude numbers. Schuller, et al. (1983) found the following expression could correlate their lift-off data:

$$
\frac{L_{f}}{D}=0.05 \mathrm{Fr}^{1 / 2}
$$

Interestingly, this result for propane flames falls precisely midway between the two lines shown on $\mathrm{Fig} .3$ for $\mathrm{CH}_{4}$ flames from $30 \mathrm{~mm}$ pipes. This result is interesting for two reasons. Firsty, based on small scale results, there ought to be a fuel dependency which this result suggests is missing in the larger scale results, at least for these two paraffins. This is to be contrasted with flame height where the normal square root of fuel density dependence in large scale has been noted (Schuller, et al. 1983). Secondly, converting $\mathrm{Eq} \cdot(6)$ to the $\mathrm{L}_{f} / \mathrm{U}$ form will result, not in a constant residence time but in a half power dependence on diameter, i.e.,

$$
\frac{L_{f}}{U}=0.016 \sqrt{D} \mathrm{~s} ; D \text { in m }
$$


Bringing this result back to a further observation of Fig. 4 might cause one to speculate even more strongly about a diameter effect.

The $1.8 \mathrm{~mm}$ data of Vanquickenborne and Van Tiggelen (1966) are also interesting regarding the diameter effect. Two different positions of the lifted flames were obtained with that diameter burner. From the "high position" the flame could drop back to the "low position" and vice versa; this happens in a seemingly random fashion. Whether this phenomenon is related to the hysteresis noted in lifted flame position when the flow rate is increasing vs. the position assumed by the flame when the flow rate is decreasing is not clear (see, for example, Fig. 2 of Gunther, Horch, and Lenze 1981). To confuse matters even more there appears to be some evidence of an additional dependence of $L_{f} / U$ upon $U$ in some of the data sets - again in a seemingly random fashion.

What is beginning to emerge is the fact that diffusion flame stability phenomena like lift-off are poorly understood and even the empirical information at small scale is not complete enough to pursue with any degree of certalnty extrapolations to larger flames. A systematic study of lift-off using the present or similar experimental facility should be undertaken. For present data reduction purposes of scaling the temperature and radiation data, use will be made of the Peters and Williams (1983) recommendation which seems on Fig. 3 at least, a reasonable representation for estimating lift-off distances. The Suris et al. (1977) suggested correlation will be used for flame height. (Note that above a Froude number of about $3 \times 10^{4}$ the actual length of the flame decreases with froude number, a result consistent with observation - $L_{f}$ approaches $H_{f}$ as blowoff is approached.) No further general- 
ization, however on the lift-off data beyond this can reasonably be made at this time.

\subsection{Flame Temperature}

Figure 5 presents the uncorrected centerline temperature rise above ambient, $\Delta \mathrm{T}=\mathrm{T}-\mathrm{T}_{0}$, from the six thermocouples (TC) plotted as a function of scaled height, $\left(z-L_{f}\right) /\left(H_{f}-L_{f}\right)$, where $z$ is the height of the TC measured from the burner exit. The attempt here is to make all the flames similar. As $Q$ is increased or decreased both lift-off and flame height change relative to the fixed thermocouple tree. The numerator gives the length or distance the thermocouple is from the beginning of the luminous region. The denominator gives the entire length of luminosity. This scaling then gives the relative position in the flame irrespective of length or lift-off. At the flame tip, $\left(z-L_{f}\right) /\left(H_{f}-L_{f}\right)$ equals 1 and at the lift-off height it equals zero. How successful this scaling is in making all flames similar has yet to be determined.

The two lines on the figure represent, for the threaded reducer, the extremes in heat release rates and offer a very graphic view of the scaling. The lower solid line, $494 \mathrm{~kW}$ flame, contains 6 data points representing a reading from each of the 6 thermocouples and spans most of the flame and to $40 \%$ beyond. As $Q$ is increased the flame height and lift off height increase until near blowoff, represented by the upper dashed curve, 1.e., the 6.99 MW case, the TC at $1 / 2$ and 1 m from the exit actually miss the flame - the lift off distance is beyond 1 meter. Those latter 4 TC's now only see the midportion or peak temperature region of this nearly transparent flame. The last 
point at a $\Delta T=1140 \mathrm{~K}$ is determined from the same $\mathrm{TC}$ which registered for the lower heat release rate case a $\Delta T=110 \mathrm{~K}$. The $6.99 \mathrm{MW}$ case is about the best pre-blow off experiment that can be obtained. Even at this setting methane gas bottles are being used up at an excessive rate.

Overall, the scallng has been successful in pulling together data representing nearly a 15-fold change in heat release rate. In detail, however, there remains systematic variations of the data among the scatter. The most obvious one and the one that will offer new information, regarding these decreasing radiative fraction - high momentum jet flames, is the increase in flame temperature with heat release rate. The data in that portion of the figure from $\left(z-L_{f}\right) /\left(H_{f}-L_{f}\right)$ equal to about 0.2 out to approximately 0.75 bounded on the bottom by the line of the lowest heat release fire and on the top by the $6.99 \mathrm{MW}$ line exhibit a weak but systemmatic variation of temperature rise with heat release rate. The length scaling of $\left(z-L_{f}\right) /\left(H_{f}-L_{f}\right)$ may have brought the data for both the rising and falling temperature portions of the flame, 1.e., small and large values of abscissa, 1nto a crude correlation but it doesn't and cannot be expected to do anything about the high temperature central portion of the flame.

All these flames are therefore not similar. In a previous report (McCaffrey 1981), correspondence was made between the flame height and radiative fraction of non-laminar diffusion flames over the entire Froude number spectrum. There exists a large intermediate range of Froude number where for a given fuel the radiative fraction is a constant, independent of burner diameter and fuel flow rate. In this regime flame height is independent of diameter varying with $Q$ to the $2 / 5^{\prime} \mathrm{s}$ power. This is a kind of similarity 
region, the portion on the $H_{f} / D$ plot, Fig. 3, prior to the "transition" at $3 \times 10^{4}$. ( $\mathrm{L}_{f}$ is still a small fraction of $\mathrm{H}_{f}$ up until this point.) In this regime temperature data might be expected to be independent of $Q$. On the other hand, at very low Froude numbers $\left(\mathrm{H}_{f} / \mathrm{D} \rightarrow 0\right)$ is the buoyancy controlled pool fire regime where similarity breaks down both for radiative fraction and flame height. Similarly at the opposite end $\left(H_{f} / D+\right.$ constant), the present interest, flame height no longer varies with $Q^{2 / 5}$ and the radiative fraction is no longer constant. It continuously decreases with increasing fuel flow reaching a non-zero value just prior to blow-off. Visually, as the flame is lifting off it gets more and more bluish and transparent until finally at blow-off all traces of yellow luminosity are gone. The ghostly bit of emission remaining up near the position where the flame height was maximum disappears with the ultimate increase in flow which brings blow-off. (There is a parallel here with the behavior of bench-top scale laminar diffusion flames. Santoro (1986) reports that his laminar $\mathrm{C}_{2} \mathrm{H}_{2}$ flame can be made almost totally blue by inerting. However, just before the last bit of yellow disappears, the flame becomes highly unstable or blows off.)

Like the non-similar buoyant end of the Froude spectrum little is known in this $H_{f} / D=$ constant region. The soot formation-oxidation process is too strongly coupled to the fluid mechanical process in these regimes to study a single representative flame and be able to generalize the behavior much beyond the particular parameters of the experiment. Here we look to empiricism to garner any bit of information possible. The rising temperature with heat release is plotted on Fig. 6 in the chemical kinetic form of the logarithm of the process rate as a function of inverse temperature. The form is purely arbitrary - any reasonable function which relates the increasing temperature 
rise in the middle portion of the flame with the heat release rate as seen on Fig. 5 would be adequate. Coupled with the radiation measurements in the following section an attempt will be made to relate the results of Fig. 6 with the soot formation-oxidation processes taking place in diffusion flames at the high momentum limit. The line on the figure represents a least squares data fit in the Arrhenius form, $\exp (-E / R T)$ with the activation energy, $E$, given as $30.8 \mathrm{kcal} / \mathrm{mole}$.

\subsection{Radiation}

Figure 7 presents the incident radiative flux from large methane diffusion flames to nearby targets as measured by two water-cooled, wide angle heat flux sensors located several meters from the flame as indicated by the schematic on the figure. They, in fact, were located in different longltudinal planes but for time-mean purposes the flames are considered to be axisyor metric. Not only are these measurements useful for estimating the flux from these flames incident to any other target once the data has been generallzed, but also, they w11l provide a baseline for estimating the suppressing effects of water spray once that data is considered. On the figure are shown for each sensor two sets of data for two different exit geometries - an internally threaded ordinary pipe reducer of exit diameter 29.2 mand a circular hole or slot, $31.8 \mathrm{~mm}$ diameter, cut stralght in an 8 m thick cap which is the end or top of a $100 \mathrm{~mm}$ diameter pipe section. The large section allows placement of the spray nozzle in the pipe for study of the effects of internal water spray on the flame behavior. The top of the spray nozzle 1 s located $6 \mathrm{~cm}$ below the exit. This, coupled with the fact that the conditions in the large section are practically stagnation, makes the presence of the nozzle less likely to significantly affect the exit flow fleld (see f1g. 1). 
If indeed the two geometries represent extremes in exit flow conditions, at least for circular apertures, then any differences between the radiative results of the two as evidenced by Fig. 7 are too subtle to discriminate - the results of the orifice appear to fall within the bounds of the scatter exhibited by the reducer. Both signals from both of the two transducers rise with gas flow rate or fire size, a not unexpected result, up to a level of about $1 / 2 \mathrm{~W} / \mathrm{cm}^{2}$ at a lateral distance of 2-3 $\mathrm{m}$ and for flow conditions of imminent blowoff, i.e., about a $7 \mathrm{MW}$ methane diffusion flame from a 30 mm nozzle.

The data contained on Fig. 7 can be generalized in terms of a model for the flame radiation, useful for estimating the flux to targets at any location and orientation. There are several methods available, none of which is totally satisfactory due to the nature of thermal radiation from flames. For jet flames the most simple geometry that immediately comes to mind to model the shape is a cylinder. Very recent compilations have appeared (Schuller et al. 1983) where effective flame heights, flame diameters, and lift off heights were determined from photographs of hydrocarbon flames from circular as well as rectangular burners of similar scale to those of interest here. Their results, in terms of source Froude number $\left(U^{2} / g D\right)$, are:

$$
\begin{array}{ll}
\text { Height } & \frac{\mathrm{H}_{f}}{\mathrm{D}}\left(\frac{\rho_{\infty}}{\rho_{e}}\right)^{1 / 2}=22.2 \mathrm{Fr}^{1 / 5} \\
\text { Diameter } & \frac{\mathrm{D}_{f}}{\mathrm{D}}\left(\frac{\rho_{\infty}}{\rho_{e}}\right)^{1 / 2}=3.5 \mathrm{Fr}^{1 / 5} \\
\text { Lift-off Height } & \frac{\mathrm{L}_{f}}{\mathrm{D}}=0.05 \mathrm{Fr}^{1 / 2}
\end{array}
$$


Note in comparing Eq. (2) with Eq. (8) that the effective flame height based on photographs is considerably less than the normal extent-of-flame-tip value. Since later a single value of temperature will be used to characterize the flame region the smaller (completely luminous volume) height may turn out to be more appropriate.

Dayan and Tien (1974) have presented a convenient analysis for a radiatively participating cylindrical fire column of uniform temperature and species concentration. It is a two parameter model of effective flame temperature, $T_{f}$, and an effective gray flame emittance $\alpha$. The flux to an external target is given as

$$
\dot{q}^{*}=\mathrm{F} \propto \sigma \mathrm{T}_{\mathrm{f}}^{4}
$$

where $F$ is the shape factor. The absorption coefficient is usually expressed in terms of an extinction coefficient, $k_{f}\left(m^{-1}\right)$ independent of geometry, and flame geometry,

$$
\alpha=1-\exp \left[-k_{f} \cdot f(D)\right]
$$

where $f(D)$ accommodates the flame geometry, e.g•, mean beam length. The measurements of $\dot{q} "$ seen on Fig. 7 together with the assumed cylinder model (Eqs. 8-10), a function of $Q$, can now be substituted into the above expressions and a flame temperature and extinction coefficient derived. These now are considered "properties" of these flames and could be used to calculate the flux to an arbitrary target. 
Figure 8 shows the derived flame properties, absorptivity and flame temperature, as a function of $Q$ for single values of the other property. The points represent the mean of the two sets of data from the two instruments shown on Fig. 7. From Eq. (11) it is obvious that an unlimited number of combinations of $\mathrm{T}_{f}$ and $\mathrm{k}_{f}$ will satisfy the data of Fig. 7. For the present, "reasonable" values of each are chosen. Note the relative sensitivity of the ordinate scales of Fig. 8 - temperature dependence to the fourth power, and $k_{f}$, a much milder dependence, i॰e•, a linearly dependent upon $k_{f}$ for thin flames. What is attempted in any two parameter model is to relate the results to some other independent measurement of either flame temperature or absorptivity.

First it is worthwhile observing some overall characteristics of the radiation from these jet diffusion flames. Without additional information, Fig. 8 on its own would indicate that as $Q$ is increased the relative radiation decreases, which is reflected either in decreased temperature with $Q$ or, for fixed flame temperature, a decreasing $k_{f}$ with $Q$. Whether it makes sense to hold either parameter constant throughout such a range of fuel flow rate is not obvious. The observation of decreasing radiation with $Q$ or gas flow rate for jet flames however, has been observed and somewhat quantified previously in terms of a decreasing radiative fraction.

The independent piece of information that can be used in the radiation model is the centerline temperature discussed in the previous section. Although the model assumes a homogeneous volume of absorbing-emitting material and certainly Fig. 5 indicates no such conformity, even axially, those measurements will nevertheless reflect the temperature variation with fire 
size in the central portion of the flame. Figure 9, exhibiting the same scales as Fig. 8, shows the derived values of $k_{f}$ given the now variable temperature variation shown on the lower portion of the figure by a solid 1ine. This is the least squares analysis of peak temperature shown in Fig. 6. Although the general shape of $k_{f}$ vs $Q$ is similar to the constant temperature result of Fig. 8, 1.e., decreasing $k_{f}$ with $Q$, the range from low to high values has increased something like a factor of two and the minimum absorptivity is now around $0.2 \mathrm{~m}^{-1}$. Having the two figures, 8 and 9 , in hand will aid in evaluating not only the changes in the levels that can be expected but also the effect of the variation on the derived property. The curve through the $k_{f}$ data is simply a least squares fit.

Figure 10 shows additional sensitivity analysis for an experiment in the middle of the group of data, 1.e., the threaded reducer, $3.3 \mathrm{MW}$ flame. Here the sensitivity to the cylindrical model chosen with regards to height and diameter of the flame as well as $T_{f}$, seen previously, can be observed. The abscissa plots the change in the 1ndependent varlables, e.g., 1.1 would indicate a $10 \%$ increase in flame height over the base value. The ordinate gives the relative change in $k_{f}$ due to that change, e.g., $k_{f}$ has decreased by about $6 \%$ to approximately 0.94. This way one 1 s able to judge how critical the dimensions of the cylindrical model of the flame, for example, would be to the calculated absorptivity. From the figure 1t would appear that flame height is not very important since the flames are quite tall already relative to the height of the sensor and that flame diameter is more critical, $D$ and $k_{f}$ come as a product (see Eq. 12). Flame temperature 1s quite critical as one would suspect basically due to thermal radiation's fourth power dependence on T. A $140 \mathrm{~K}$ temperature differential at a level of $1400 \mathrm{~K}$ is $10 \%$ and would 
correspond to a $60 \%$ increase in $k_{f}$ on the low side or a $35 \%$ decrease in $k_{f}$ on the high temperature side. Still when these numbers get fed back to Eq. (12), the expression for flame emittance, a much milder variation results - provided the flame diameter is of order $1 \mathrm{~m}$ or less which is true in the present case. This is not the case for more usual extinction coefficients which are on the order of $1 \mathrm{~m}^{-1}$, the point where the exponential function is changing rapidly. The present model of the quite optically thin high momentum $\mathrm{CH}_{4}$ flames is therefore quite robust as regards temperature changes.

We now have a "model" for the radiative field associated with high momentum $\mathrm{CH}_{4}$ diffusion flames. Recall from Fig. 9 the lower portion represents an independent measurement of the way a representative flame temperature varies with heat release rate. That information coupled with the radiometer measurements and the cylindrical flame model yields the upper portion of the figure, the extinction coefficient, $k_{f}$, as a function of fire size. There is another way of expressing the information contained on Fig. 9 which is useful and is such that direct comparison with the literature can be made. One can calculate the radiative fraction, using the flame temperature, geometry and absorption coefficient data of the model.

Using Eq. (11), the view factor for a surface element very far, $x$, from the flame is:

$$
F=\frac{1}{\pi} \frac{D_{f}^{H_{f}}}{x^{2}}
$$

The flame emittance, $\alpha$, can be expressed (see Dayan and Tien 1974) for far distances as: 


$$
a=1-\exp \left[-0.7 k_{f} \cdot D_{f}\right]
$$

The definition used here for the radiative fraction is the total radiative power output, obtained from the flux to the surface element far from the flame multiplied by the total surface area of the hemisphere, $4 \pi x^{2}$, divided by the nominal heat release rate of the fire. This assumes a point source and uniform flux at the surface of the sphere of radius $x$, even though to calculate the flux at $x$ we will use the cylindrical model of the flame. The radiative fraction, $x$ is therefore:

$$
x=\frac{Q_{r a d}}{Q}=\frac{4 \pi x^{2} \dot{q}^{\prime \prime}}{Q}=\frac{4}{Q} D_{f} H_{f} \sigma T_{f}^{4}\left[1-e^{-0.7 k_{f} D_{f}}\right]
$$

where Eq. (11), (13) and (14) are substituted for $\dot{q}^{*}$. Using the cylindrical model for $\mathrm{D}_{f}$ and $\mathrm{H}_{\mathrm{f}}, \mathrm{Eq} \cdot(8)$ and $(9)$,

$$
x=1.124 \times 10^{-12} \frac{T_{f}^{4}}{Q^{1 / 5}}\left[1-\exp \left(-0.0196 k_{f} Q^{2 / 5}\right)\right]
$$

where $T_{f}$ is in $K, Q$ in $k W$, and $k_{f}$ in $m^{-1}$. The least squares expression for $T_{f}$ and $k_{f}$ as a function of $Q$ from Fig. 9 can be substituted to obtain the final result.

A plot of this derived or semi-calculated model radlative fraction result is shown on Fig. 11 along with literature measurements. In place of $Q$ the abscissa is the square root of Froude number. (For the present pure methane gas from a $30 \mathrm{~mm}$ exit diameter $\mathrm{U} / \sqrt{\mathrm{gD}}=0.0769 \mathrm{Q}, \mathrm{Q}$ in $\mathrm{kW}$. ) What is seen on Fig. Il is the high end of the buoyancy-momentum Froude number spectrum (McCaffrey 1981). The left portion is the intermediate region, Becker's 
(1982) "natural convection limit". Here flame height is independent of diameter and the radiative fraction is constant. Although not evident from the data shown on the figure this region of constant radiative fraction extends down, using larger and large diameter burners, many orders of magnitude in Froude number (McCaffrey 1981). At higher Froude numbers $\sim 0\left(10^{4}\right.$ ) flame height becomes constant, lift off becomes significant and the radiative fraction begins to decrease as blowoff is approached. That is the region where most of the data on Fig. 11 is contained. The decreasing radiative fraction corresponds visibly to less yellow luminosity and hence indicates perhaps some interference with the soot formation-oxidation process. Recall that temperatures are rising in this regime. Flame particulate decrease with rising temperature or jet velocity has been noted previously by Brzustowski, et. al. (1975) for smaller diffusion flames.

The derived curve on Fig. 11, designated "present calculation", encouragingly splits the available data indicating both a reasonable level of $X$ as well as variation of $x$ with jet velocity. On the top of the figure are some reference benchmarks. The quoted flame height transition at $F r=3 \times 10^{4}$ is seen and appears to be well into the decreasing $x$ regime rather than coinciding exactly with the start of the regime. Another reason for the call for a systematic study of lift off would be to exactly determine where that feature of the region begins relative to these other two, i.e., the start of the decreasing radiative fraction and blowoff. The end of the region is marked by the "blow off" designation - the 5 mm is from Kalghatgi (1981); the $30 \mathrm{~mm}$ is the present result. The variation from 5 to 30 ought to go as the $1 / 2$ power if lift off velocity is linear with diameter. (Becker (1982) has data for smaller diameter burners which are not shown since a stabilizing gas 
was used to prevent lift off and hence that data extends well beyond the normal blow-off for pure $\mathrm{CH}_{4}{ }^{\circ}$ )

Using the least squares expression for $T_{f}$ and $k_{f}$ as a function of $Q$ from Fig. 9 the quantity $\alpha \sigma T_{f}^{4}$ can be calculated. This emissive power varies only slightly with $Q$ or fire size: equal to about $2.9 \mathrm{~W} / \mathrm{cm}^{2}$ at $1 \mathrm{MW} \mathrm{rising}$ to about $3.3 \mathrm{~W} / \mathrm{cm}^{2}$ at $7 \mathrm{MW}$, or at blow-off for this $30 \mathrm{mmD}$ configuration. This is a much milder variation with size and a somewhat higher level than that found by Sonju and Hustad (1985). They chose to correlate their data in terms of the radiating helght of a cylindrical surface emitter

$$
\alpha \sigma T^{4}=0.5+0.39\left(H_{f}-L_{f}\right)
$$

in $\mathrm{W} / \mathrm{cm}^{2}$ with the heights in $\mathrm{m}$. The present absorbing-emitting results come out to be significantly higher at small fire sizes but with little variation with increasingly larger scale, 1.e.,

$$
\alpha \sigma T^{4}=2.6+0.13\left(H_{f}-L_{f}\right)
$$

Note that Eqs. (8) and (10) were used for the present calculations.

\subsection{Effect of Water Spray}

The effect of water spray on the centerline thermocouple readings can be seen in Figs. 12 and 13 which show temperature as a function of helghe for a variety of fire sizes. For clarity, falred curves are drawn between the dots representing the data points. (For repeated runs vertical lines are used, the 
extremities of which span the data scatter.) The parameter is the ratio of the mass flow rate of water to that of the gas, $\dot{\mathrm{m}}_{\mathrm{H}_{2}} \mathrm{O} \dot{\mathrm{m}}_{\mathrm{CH}_{4}}$, a natural scaled quantity used previously in small scale studies.

In general there appear to be two dominant effects emerging from the figures: peak temperatures are lowered and relative positions in the flame have been shifted to higher $z$, i.e., the flame is being pushed off or lifted above its non-sprayed position. Both effects tend to increase with the amount of spray. For certain experiments, notably the $2.3 \mathrm{MW}$ flame there exists confusion regarding a temperature inversion when viewed in a physical height coordinate. A portion of this can be accounted for by the shift of the flame, i.e., hotter portions are at higher elevations. Evans (1985) in a subsequent study using external sprays found that the remainder of the anomalies in the upper regions disappeared with longer sampling times and more restrictions on what constituted acceptable weather variations for running the experiments. The lower and peak temperature regions appear unaffected.

The first of the effects, the lowering of the temperatures, is more easily quantified on Fig. 14 which shows the peak temperature plotted against water flow for the data from the previous two figures. In general the temperature data appear to decrease with scaled water flow rate as a group, i.e., there is no obvious ordering of the data aside from the small $T$ increase with $Q$ noted earlier for the case of the zero water flow base line, seen here at the ordinate. The one exception is the largest, $4.6 \mathrm{MW}$ flame which extinguished slightly beyond the last recorded data on the lower portion of Fig. 13. At $\dot{\mathrm{m}}_{\mathrm{H}_{2}} / \dot{\mathrm{m}}_{\mathrm{CH}_{4}}$ equal to 0.23 the flame was suppressed but stable; at $\dot{\mathrm{m}}_{\mathrm{H}_{2} \mathrm{O}} / \dot{\mathrm{m}}_{\mathrm{CH}_{4}}$ equal to 0.34 the flame went out. Based on the small size of the 
temperature reduction at these water flow rates it appears that extinguishment resulted not from a thermodynamic-like cooling effect to some lower limit temperature but rather to the slight, further lift or push to an already lifted flame beyond some flame stabilization distance. There would be a strong analogy in this interpretation in going to blow-off for an unsprayed flame. Presumably those suppressed flames which did not extinguish even with rates of water flow ten times that amount, as seen on the figure, were that much more stably configured. These observations are quite similar to small scale $\mathrm{H}_{2}$ flame extinguishment with sprays seen previously (McCaffrey 1984) where temperature measurements alone would not have indicated an unstable situation.

Shown in Fig. 14 by the solid lines are equilibrium calculations for the $\mathrm{CH}_{4} / \mathrm{air} / \mathrm{H}_{2} \mathrm{O}(\ell)$ system for arbitrary equivalence ratios of 0.45 and 2.15 . These were chosen on each side of stoichiometry in order to approximately match the unsprayed temperature results. As one might travel with the gas from very fuel rich at the pipe exit through a variety of $\phi$ to very lean conditions near the flame tip the peak temperature region of the flame might straddle those $\phi$. The trend of the data sort of matches the trend of the calculation even though the relationship between a real diffusion flame sprayed with water and an adiabatic perfectly mixed system calculation 1 s not clear. [Recent work by Jeng, Chen, and Faeth (1982) have shown that part1al equilibrium methods have yielded some reasonable success regarding the characterization of $\mathrm{CH}_{4}$ jet flames.] The calculated temperature will tend to decrease without limit as the relative amount of water is increased. Perhaps the data would indicate a weakening of the trend to decrease, 1.e., reach an asymptote and then perhaps the flame would go out. Thermodynamics is certainly not going to explain the $4.6 \mathrm{MW}$ extinguishment at $\dot{\mathrm{m}}_{\mathrm{H}_{2}} \mathrm{O}^{/ \dot{\mathrm{m}}_{\mathrm{CH}_{4}}}=0.34$. 
Some quantification of the second effect of sprays seen on Figs. 12 and 13, namely that of the "push off" effect, can be estimated from Fig. 15. Two arbitrary positions in the flame, the height where $\Delta T=500 \mathrm{~K}$, the filled symbols, and the height where $\Delta T=0$, that is the extrapolation to $\Delta T=0$ from Figs. 12 and 13, the open symbols, are plotted against scaled water flow rate. The ordinate is the ratio of the positions of the sprayed, or wet ( $W$ ), to the unsprayed, or dry (D). The presumption is that the same temperature would be representative of similar reaction regions in the flame and that the water has not otherwise perturbed the flame. We are tacitly assuming that the two effects are distinct. The similarity between the $\Delta T=0$ data and the data for the temperature in the reaction zone is encouraging in this regard. The ordinate has been normalized by the heights or the flame positions corresponding to the loci of $\Delta T=500$ and $\Delta T=0$ for the situation without water spray which does a reasonable job of pulling together different fire sizes. Those zero water flow values for $\Delta T=0$ are consistent with Fig. 3 which shows liftoff height vs. Froude number thus strengthening the confidence in the results of the rather liberal extrapolation made of the data on Figs. 12 and 13.

The results seen on Fig. 15 can be used to estimate the degree of additional lift-off height the spray will provide to an otherwise undisturbed flame. In fact a model can easily be constructed of the process involved in the kind of extinguishment discussed previously concerning the $4.6 \mathrm{MW}$ flame on Fig. 14. Frow Fig. 3 the lift-off height for a given fire size will be known. (The need for a systematic study of large fire lift-off in order to improve the accuracy of what is to follow ought to be evident.) This height is then increased by the results of Fig. 15, i.e., 


$$
\frac{\left(\mathrm{L}_{\mathrm{f}} / \mathrm{D}\right)_{\mathrm{W}}}{\left(\mathrm{L}_{\mathrm{f}} / \mathrm{D}\right)_{\mathrm{D}}}=1+\mathrm{f}\left(\dot{\mathrm{m}}_{\mathrm{H}_{2} \mathrm{O}} / \dot{\mathrm{m}}_{\mathrm{CH}_{4}}\right)
$$

where subscripts $W$ and D refer to conditions with (wet) and without (dry) water spray, respectively. The function $f$ is a sultable representation of the increased lift data seen on the figure. It should be able to be calculated through a sufficiently detailed model of the momentum exchange between a jet encompassing a spray. When $\left(L_{f} / D\right)_{W}$ is increased to the critical value by the spray, blowoff results. Using Eq. (4) for $\left(L_{f} / D\right)_{D}$, in terms of heat release, Q:

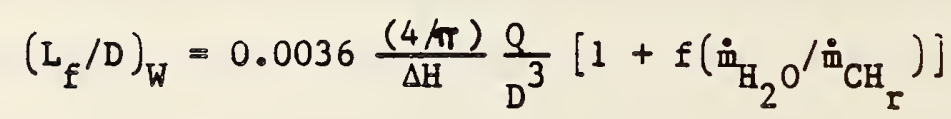

For $\mathrm{L}_{\mathrm{f}} / \mathrm{D}$ critical equal to a constant, say 50 (see Peters and Williams, 1983), and a linear approximation to the data of Fig. 15 (the straight line on the figure), the required flowrate of water for the kind of extinguishment discussed above is:

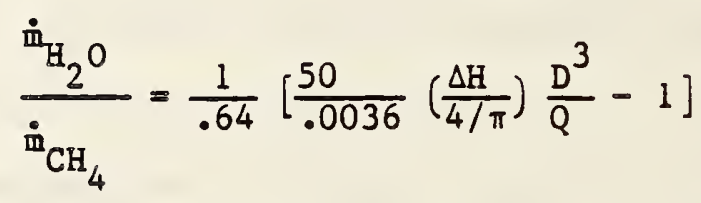

where 0.64 is the slope of the fourteen data of F1g. 15. That number (and the Iinear approximation) together with the critical $\mathrm{L}_{\mathrm{f}} / \mathrm{D}, 1 . e, 50$ and the variation of $L_{f} / D$ with Fr number, the 3.6 ms number, constitute considerable experimental information whose accuracy and range are yet to be established, especially for large flames. Nevertheless, Eq. (18) may provide for first order effects with regards to the expected variation of water requirements with scale. Note that the 3.6 ms could be replaced by Kalghatg1's (1984) expression for $L_{f} / U$, i.e., Eq. (5), for different gas mixtures. 
For the present $0.03 \mathrm{mD}$ burner using $\mathrm{CH}_{4}$ gas, the critical water flow rate becomes

$$
\frac{\stackrel{\circ}{\mathrm{m}}_{\mathrm{H}_{2} \mathrm{O}}}{\dot{\mathrm{m}}_{\mathrm{CH}_{4}}}=\frac{1}{0.64}\left[\frac{10,000}{\mathrm{Q}(\mathrm{kW})}-1\right]
$$

For the data show on Fig. 14, the three smaller fires all would require flow rates beyond what is seen on the figure, beyond $\dot{\mathrm{m}}_{\mathrm{H}_{2}} \mathrm{O}^{/ \dot{\mathrm{m}}_{\mathrm{CH}}}=3$ for this blowoff kind of extinguishment. Only for the $4.6 \mathrm{MW}$ fire would extinguishment be visible in the range of the abscissa of Fig. 14. The number calculated by Eq. (19) is about 1.8 whereas extinguishment occurred at a flow rate ratio of 0.34. We might perhaps expect the analysis to be conservative in requiring more water since any dilution or cooling effects have been ignored. However, given the small amount of experimental information and the contention of isolated effects used to generate the above, the qualitative agreement seen in the four fire sizes is probably all that can be expected and speculation about any quantitative differences, at this stage, is probably fruitless.

The final effect of water spray observed during this work was that of a reduction in radiation as observed by the heat flux sensors. Figure 16 shows the average signal decrease of the sensors as a function of $\dot{\mathrm{m}}_{\mathrm{H}_{2} \mathrm{O}} / \dot{\mathrm{m}}_{\mathrm{CH}}$ using solid symbols. Shown by open symbols are the temperature data seen on Fig. 14 normalized by the value for zero water flow raised to the fourth power. Both the heat flux and the gas temperature fall as the amount of water sprayed increases. The very large decrease in temperature to the fourth power is not, however, being reflected in the sensor output. Something is preventing the radiation sensors from realizing the tremendous cooling that is being observed by the thermocouples due to the water. And that something appears to be increasing with increased water flow. 
From Eq. (11) which is the expression which quantifies what the sensor ought to read, one can 1mmediately postulate that either the flame emissivity or the view factor or both must be increasing in order to compensate for the decreased temperature levels. Since it is known that the spray lifts the flame vertically, which for the present locations of the sensors will not slgnificantly improve the view and may, In some cases, tend to decrease the view factor, we will look to increased absorptivity in order to reconclle this apparent dilemma. It ceases to be a dilemma when it is reallzed that water when sprayed into a flame, besides disturbing the flame, will be evaporated and heated to a significant temperature and 1tself then becomes a significant IR radiator. And the more water the more radiating volume. This is exactly true for a non-sooting flame. However, for flames with appreciable soot the water may exhibit a far greater Influence by interfering with the soot formation-oxidation process. Since it is expected that the amount of soot will be controlling the optical properties of these very luminous diffusion flames the emissivity will decrease and not increase with the amount of water sprayed. Presumably the steam will still be radiating but not sufficiently to be able to overcome the decrease due to the reduced particulate emission. (In subsequent calculations the additional lift due to the spray has been incorporated into the radiation model.) However, we need not be too concerned here with interfering with the soot formation-oxidation process since our high velocity $\mathrm{CH}_{4}$ jet flames are almost soot free.

Returning to the simple gray, cylindrical model of the flame an effective absorptivity can be determined. Recall that the fire size, Q (for flame dimenstons and view factors) and the measured heat flux are input to a calculation which then produces a varlety of temperatures and absorptivities which 
will satisfy the model (see Fig. 8). Now, the experimental temperatures shown on Fig. 14 are used to determine the appropriate $k_{f}$ for both the dry base line and the sprayed data. The results are shown on Fig. 17 in the form of $k_{f W} / k_{f D}$, that is, the increase in absorptivity due to the water spray as a function of water flow (solid symbols) or the difference between $\dot{q}_{w} / \dot{q}_{d}$ and $\left(T_{w} / T_{d}\right)^{4}$ seen on Fig. 16 (open symbols). That increased $k_{f}$ is what is going to be required in order to reconcile the very low temperature data with the only moderately low heat flux data. At $\dot{\mathrm{m}}_{\mathrm{H}_{2} \mathrm{O}} / \dot{\mathrm{m}}_{\mathrm{CH}_{4}} \sim 3$, for example, a factor of 2 increase in absorptivity will be required.

Knowing the size and variation of the increased $k_{f}$ it is now a matter of simply obtaining water vapor emissivities from the literature in order to confirm the above. That is, the increased emissivity required to reconcile the temperature data is determined from the radiation model of the flame, i.e., Fig. 17. An attempt will be made to predict that increase based on an emissivity chart for water vapor (Hottel 1967) which requires knowing the temperature and path length and will yield a partial pressure of water for a given emissivity. That partial pressure can then yield information about flame entrainment which can be checked or at least compared with small scale jet flame entrainment measurements of Ricou and Spalding (1961). For that, a model will be constructed which attempts to determine an "equivalent" fluid for the configuration of a water spray inside the $\mathrm{CH}_{4}$ jet to be used for source conditions needed for the entrainment calculation. The idea of increased emissivity due to flame suppression by water spray can then rest on firmer ground. 
The following calculation will utilize a range of flame diameter or path length so as to set brackets on the final result. High and low values of $D$ are chosen since the result is quite dependent on the value of $D$ and it is difficult to assess, a priori, what value of $D$ is appropriate. The reason for the difficulty is the counter effects of increasing flame volume due to the increased mass injected (steam volume is 1700 times that of liquid water). It will be seen that the entrained flow is proportional to the injected flow. This is countered by the tendency of the flame to entrain at a lower rate due to buoyancy effects brought about by the increased density of the fluid, 1.e., liquid drops, at the source of the jet.

Even if the additional mass or volume of fluid entrained were known, a priori, how it is proportioned between diameter and height would be still unknown. From Fig. 10 it is obvious that putting all the volume into an increased dlameter would result in a far different $k_{f}$ then having all the mass increase the flame height. The characteristics of the spray and jet-spray interaction and a host of other things would have to be known in a much more detailed manner than is currently available in order to do this problem.

A scheme for determining a reasonable range of $\mathrm{D}$ which avoids some of these difficulties is as follows: let $D$ extend from a base Ine established solely by the heat release rate of the fire, Eq. (9) to a maximum value of D determined from Fig. 10, the sensitivity analysis of the radiation model. (Figure 17, for example, uses the base line or the "dry" value of $D$ in the calculation.) From Fig. 10 as $D$ is increased $k_{f}$ decreases. A nacural upper limit on $D$, therefore, would occur when $k_{f}$ drops to such a value as to el1minate the advantage of the radiating steam, $1 . e \cdot, k_{f}$ falls to the dry value 
predicted by the model. From Fig. 10 and the data on Fig. 17, a D was determined which will be designated $D_{w}$ for wet, maximum diameter. A crude fit to those results relative to $D$ which is the value if no change in volume results from the spray, i.e., Eq. (9), is:

$$
\frac{D_{w}}{D}=1+2.33 \times 10^{-6} \cdot Q^{3 / 2} \cdot \frac{\dot{m}_{H_{2}} \mathrm{O}}{\dot{\mathrm{m}}_{\mathrm{CH}_{4}}}
$$

where $Q$ is in $\mathrm{kW}$. This is purely a data fit and as yet of unknown physical significance. (A form similar to this would be suitable for representing the solid symbols of Fig. 17.) Most of the data yields an incremental increase in diameter of about $10 \%$ with the larger water flow rates rising to about $30 \%$. These values are quite a bit smaller than ones calculated by assuming that the diameter is taking up most of the increased volume and that the entrained flow is directly proportional to injected flow, i.e., $D_{w} / D$ from $E q \cdot(20$ ) is much less than $\sqrt{1+\dot{\mathrm{m}}_{\mathrm{H}_{2} \mathrm{O}} / \dot{\mathrm{m}}_{\mathrm{CH}_{4}}}$. We cannot at this juncture put the rest of the additional volume into an increased flame height because the total is still unknown.

Having now a seemingly reasonable range over which $D$ might vary, the radiation model is run again, this time with the larger D (recall that Fig. 17 used the heat release rate calculated for a dry value of D). For both diameters the procedure is the same. Assume for convenience an expression like Eq. (12) for absorptivity for both dry and. wet cases. The difference between the two will be assumed due to the water vapor:

$$
\alpha_{D}=1-\exp \left(-0.7 \cdot D \cdot k_{E_{D}}\right)
$$




$$
\alpha_{w}=1-\exp \left(-0.7 \cdot D \cdot k_{f}\right)
$$

where $k_{f_{w}}$ now includes the additional emitter or $k_{f_{W}}=k_{f_{D}}+k_{f_{H_{2} O}}$, and hence the separate contribution to the radiation due to water vapor is:

$$
a_{H_{2} 0}=1-\left(\frac{1-\alpha_{w}}{1-\alpha_{D}}\right)
$$

Figure 18 shows the calculated $\alpha_{\mathrm{H}_{2} \mathrm{O}}$ for both extremes of diameter.

With that absorptivity (assumed equal to emissivity) and temperature, a value of the product of path length and partial pressure is obtained from the water vapor emissivity chart (Hottel 1967). Dividing this number by path length yields the derived vapor pressure of water in the flame. Figure 18 shows a plot of water vapor pressure, $\mathrm{P}_{\mathrm{w}}$, versus $\dot{\mathrm{m}}_{\mathrm{H}_{2}} \mathrm{O} / \stackrel{\mathrm{m}}{\mathrm{CH}}_{4}$. The symbols represent a simple average, the lines extend to the two diameter results with the upper extent corresponding to the calculation using the small or "dry" diameter. Like the necessity of a being larger, one would require more emitting vapor if the optical path were smaller. Judging by the amount of vapor required the amount of entrained fluid will turn out to be small.

Figure 18 now allows an estimate of the amount of flame entrainment. It is, normalized by the source flow, $\dot{\mathrm{m}}_{\mathrm{o}}=\dot{\mathrm{m}}_{\mathrm{CH}_{4}}+\dot{\mathrm{m}}_{\mathrm{H}_{2}} \mathrm{O}$, equal to:

$$
\frac{\stackrel{\circ}{\mathrm{m}}_{\mathrm{ENT}}}{\dot{\mathrm{m}}_{\mathrm{O}}}=\frac{29 / 18}{\mathrm{P}_{\mathrm{w}}}\left[1+1 /\left(\dot{\mathrm{m}}_{\mathrm{H}_{2} \mathrm{O}} / \dot{\mathrm{m}}_{\mathrm{CH}_{4}}\right)\right]^{-1}-1
$$

assuming total pressure is 1 atm and that most of the total gas consists of entrained air. This estimate of entrainment can now be compared with an 
independent calculation of flame entrainment which ought to validate somewhat the determined partial pressure of water vapor seen on Fig. 18.

Ricou and Spalding (1961) have correlated small scale flame entrainment data in the following form*:

$$
\frac{\dot{m}_{\mathrm{ENT}}}{\dot{\mathrm{m}}_{0}} \mathrm{Fr}_{c}^{-1 / 2}=0.165\left[\frac{\mathrm{H}}{\mathrm{D}}\left(\frac{\rho_{\infty}}{\rho_{\mathrm{O}}}\right)^{1 / 2} \mathrm{Fr}_{c}^{-1 / 2}\right]^{5 / 3}
$$

where $H$ is the entrainment length and Fr is a Froude number which includes buoyancy effects due to combustion.

$$
F r_{c}=\frac{C_{p} T_{\infty}}{\dot{m}_{\mathrm{CH}_{4}} / \dot{\mathrm{m}}_{0} \Delta \mathrm{H}} \cdot \frac{U_{0}^{2}}{g D}\left(\frac{\rho_{\infty}}{\rho_{0}}\right)^{1 / 2}
$$

for injected fluids at ambient temperature. Eq. (25) can be written in the following form:

$\frac{\dot{\mathrm{m}}_{\mathrm{ENT}}}{\dot{\mathrm{m}}_{\mathrm{o}}}=0.165 \cdot\left(\frac{{ }_{\mathrm{P}_{\infty}}^{\mathrm{T}_{\infty}}}{\Delta \mathrm{H}}\right)^{-1 / 3} \cdot\left(\dot{\mathrm{m}}_{\mathrm{CH}_{4}} / \dot{\mathrm{m}}_{0}\right)^{1 / 3} \cdot\left(\frac{\mathrm{H}}{\mathrm{D}}\right)^{5 / 3} \cdot\left(\frac{\rho_{\infty} \sqrt{\mathrm{gD}}}{\rho_{0} U_{0}}\right)^{2 / 3}$

From Eq. (25) it is clear that entrainment varies inversely with source Froude number to the $1 / 3$ power and here, Eq. (27), the explicit dependence upon the product $\rho_{0} U_{0}$ at the source is seen. For a pure gas there is no difficulty, for a gas encapsulating a water spray the situation is not so clear. Perhaps an effective $\rho_{0} U_{0}$ could be developed.

*The slope and intercept are given by Putnam, A.A. and Speich, C.F. (1963), A Model Study of the Interaction of Multiple Turbulent Diffuston Flames, Ninth Combustion Symposium (Int.), Pittsburgh, USA, p. 867. 
For the dry case of pure $\mathrm{CH}_{4}, \dot{\mathrm{m}}_{\mathrm{CH}_{4}} / \dot{\mathrm{m}}_{\mathrm{O}}=1$, flame height varies with Froude number to the $1 / 5$ [Eq. (8)] and hence source conditions for the dry case drop out of the equations. Equation (27) predicts $\frac{\dot{\mathrm{m}}_{\mathrm{ENT}}}{\dot{\mathrm{m}}}=146$ for all the cases of interest here. The stoichiometric air requirement for $\mathrm{CH}_{4}$ is $17.3 \mathrm{~kg}$ air/kg $\mathrm{CH}_{4}$ and therefore $146 / 17.3=8.4$ times the necessary air has been entrained up to the flame tip. This is about half the value obtained for $\mathrm{CH}_{4}$ diffusion flames burning in a pool configuration where buoyancy is much more dominant (McCaffrey 1983). Note for the buoyant case the flame length is only several diameters high versus several hundred for the jet.

It is interesting to go the other way and eliminate buoyancy and estimate entrainment. The Ricou and Spalding (1961) result in the absence of buoyancy (but allowing for different source density than the surroundings) is:

$$
\frac{\stackrel{\circ}{\mathrm{m}}_{\mathrm{ENT}}}{\dot{\mathrm{m}}_{\mathrm{O}}}=0.32 \frac{\mathrm{H}}{\mathrm{D}}\left(\frac{\rho_{\infty}}{\rho_{0}}\right)^{1 / 2}
$$

which for $\mathrm{CH}_{4}$ is $0.43 \mathrm{H} / \mathrm{D}$. For the larger fires $\mathrm{H} / \mathrm{D} \sim 220$ (F1g. 3) yielding an entrained to source flow of about 94 compared to 146 for the flame case. (Using Eq. 8 for effective flame height the 94 would be correspondingly lower.) By lighting-off the methane jet, therefore, one can increase the entrainment by 50\%. By burning it in a more buoyant configuration by, for example, increasing $D$, even much larger entrainment rates are avallable. These examples illustrate the 1mportance of buoyancy and the range of values that could be expected. Anything that changes the source conditions like the introduction of a heavy fluid such as a water spray into the gas stream w111 obviously then have a significant effect on flame entrainment. 
The question now arises as to how to estimate an "effective" source $\rho_{0} U_{0}$ for use in Eq. (27). Probably the simplest method is to find a uniform "equivalent" fluid the properties of which reflect the liquid spray (the details of which little is known) in the methane stream.

Consider an equivalent stream of mass flow equal to the sum of the mass flows of the methane and water spray streams.

$$
\dot{\mathrm{m}}_{\mathrm{o}}=\dot{\mathrm{m}}_{\mathrm{CH}_{4}}+\dot{\mathrm{m}}_{\mathrm{H}_{2} \mathrm{O}}
$$

Similarly, let the momentum of the equivalent stream equal the sum of the individual momenta of the two streams.

$$
\dot{\mathrm{m}}_{\mathrm{O}} \mathrm{V}_{\mathrm{O}}=\dot{\mathrm{m}}_{\mathrm{CH}_{4}} \mathrm{~V}_{\mathrm{CH}_{4}}+\dot{\mathrm{m}}_{\mathrm{H}_{2}} \mathrm{O}_{\mathrm{H}_{2} \mathrm{O}}
$$

We can immediately solve for the velocity of our hypothetical equivalent stream. It is the mass flow rate-weighted velocity.

$$
V_{0}=\frac{1}{1+r} V_{\mathrm{CH}_{4}}+\frac{1}{1+I^{-1}} \mathrm{~V}_{\mathrm{H}_{2} \mathrm{O}}
$$

where $I$ is the mass flow rate ratio, $I=\dot{\mathrm{m}}_{\mathrm{H}_{2}} \mathrm{O}_{\mathrm{m}_{\mathrm{CH}}}$.

In steady flow the density of a mixture of two simple fluids is, again, the mixture fraction-weighted density, i.e.,

$$
\rho_{\circ}=\frac{1}{1+r} \rho_{\mathrm{CH}_{4}}+\frac{1}{1+r^{-1}} \rho_{\mathrm{H}_{2}} \mathrm{O}
$$


Taking the product and simplifying,

$$
\rho_{\mathrm{O}} V_{\mathrm{O}}=\rho_{\mathrm{CH}_{4}} V_{\mathrm{CH}_{4}} \frac{(1+\phi r)\left(1+A r^{2} / \phi\right)}{(1+r)^{2}}
$$

where $A$ is the ratio of the individual stream outlet areas, i.e., $A={ }_{\mathrm{CH}_{4}} / \mathrm{A}_{\mathrm{H}_{2} \mathrm{O}}$ and $\phi$ is the ratio of density of water (or soon to be, spray) to gas, $\phi=\rho_{\mathrm{H}_{2} \mathrm{O}} / \mathrm{\rho}_{\mathrm{CH}}$. The reason $\phi$ will be a parameter in what 1s to follow is that the water stream is not a simple fluid but rather a spray of very complex properties, e.g., unknown mean drop size, size distribution, particle velocities, volume fraction of liquid, etc. For two simple fluids Eq. (33), utilizing the two appropriate conservation laws, Eqs. (29) and (30), would be perfectly general, with $\phi$ equal to a constant. Here we will allow $\phi$ to vary within reasonable limits and observe the behavior of the final result.

As $r$ approaches zero the value of $\rho_{0} V_{0}$ from Eq. (33) approaches that of $\mathrm{CH}_{4}$ and as $\mathrm{r}$ grows extremely large $\rho_{0} \mathrm{~V}_{0}$ approaches that of $\mathrm{H}_{2} \mathrm{O}$, both results independent of the parameters $\dot{\phi}$ and A. For simpliclty we w1ll fix A at 21.97 , the ratio of the squares of diameters of the two outlets, and only vary $\phi$. The largest value of $\phi$ would be that of a solfd stream of water, the actual density of liquid water to that of methane, 1.e., 1000/.679. The value of the real spray will be less since the stream will contain not a solid stream but Individual drops surrounded by methane gas. The lower limit for $\phi$ would approach 1 as the volume fraction of the liquid drops approaches zero - the density of the water stream approaches that of the $\mathrm{CH}_{4}$ gas. For $\phi=1$, Eq. (33) is the same as a mass flow rate-welghted calculation of $\rho_{0} V_{0}$, a strong function of $r$. For $\phi=1473, \rho_{0} V_{0}$ is obviously very large and is weakly dependent on $\mathbf{r}$. 
The final step is to calculate $\dot{\mathrm{m}}_{\mathrm{ENT}} / \dot{\mathrm{m}}_{\mathrm{O}}$ from Eq. (27) using the range of described above for determining the hypothetical equivalent source function, $P_{0} V_{0}$. Figure 19 shows the comparison of $\dot{m}_{E N T} / \dot{m}_{0}$ determined from the radiation and temperature measurements through derived water vapor partial pressure (ordinate) as against $\dot{\dot{m}}_{\mathrm{ENT}} / \dot{\mathrm{m}}_{0}$ calculated from the Ricou and Spalding formulation (abscissa) using the range of $\phi$. The symbols represent simple arithmetic averages of the high and low value of each calculation, the lines extend to the full range of the calculations. Vertically, the larger or "wet" diameter corresponds to the upper extent and the lower extent to the smaller or "dry" D used in the radiation calculation. Again, larger path lengths require less mass of radiating material and less participating material means more entrainment. Horizontally, the left size of the $\phi$ range corresponds to a solid stream, very large values of $\rho_{0} V_{0}$ with little variation with either heat release rate or water flow rate ratio. On the right, approaching larger void volumes, the variation with water flow rate is picked up. Also on the figure, for reference, is the entrained values of a jet and two flames without spray as discussed above.

Judging by the figure the entrainment rate for sprayed flames is extremely low vs. non-sprayed flames and decreases with increasing $\dot{\mathrm{m}}_{\mathrm{H}_{2} \mathrm{O}} / \dot{\mathrm{m}}_{\mathrm{CH}} \cdot$ Recall, however, that $\dot{m}_{0}$ in the denominator contains water flow as well as methane. To convert the numbers on Fig. 19 to $\dot{\mathrm{m}}_{\mathrm{ENT}} / \dot{\mathrm{m}}_{\mathrm{CH}}$, the entrainment to flame gases only, multiply by $1+\dot{\mathrm{m}}_{\mathrm{H}_{2}} \mathrm{O} / \dot{\mathrm{m}}_{\mathrm{CH}_{4}}$. If that is done all the data will yield an entrained flow beyond the stolchiometric value for methane although just barely for the higher values of spray. 
Although Fig. 19 is certainly supportive of the increased emissivity with water spray idea it should be approached with caution. As previously mentioned for sooty flames the water will probably have a more profound effect on the particulate creation-destruction processes and hence affect radiation differently for those cases. Also there is a great deal of quantitative uncertainty built into both the ordinate and abcissa of Fig. 19. Most notably the use of variable $\phi$ as a representative for spray dynamics as well as the homogeneous radiation model for a sprayed flame must be included. Obviously, further experimentation is warranted. In the meantime, the "reasonableness" of Fig. 19 remains intriguing.

\section{ACKNOWLEDGMENTS}

Thanks are due R. Zile and W. Hayes who assisted with the construction of the test facility, instrumentation and data taking; as are thanks due H. Baum for fruitful discussions. Portions of this work was sponsored by the Department of the Interior, Minerals Management Service, John Gregory and Ed Tennyson, contract monitors. 


\section{REFERENCES}

Annushkin, Y.M. and Sverdlov, E.D. (1979). Stability of Submerged Diffusion Flames in Subsonic and Underexpanded Supersonic Gas-Fuel Streams, Combust. Explosion and Shock Waves 14, 597.

Becker, H.A. and Liang, D. (1978). Visible Length of Vertical Free Turbulent Diffusion Flames, Combustion and Flame 32, 115.

Becker, H.A. and Liang, D. (1982). Total Emission of Soot and Thermal Radiation by Free Turbulent Diffusion Flames, Combustion and Flame 44, 305.

Brzustowski, T.A., Gollahalli, S.R•, Gupta, M.P•, Kaptein, M. and Sullivan, H.F. (1975). Radiant Heating from Flares, American Society of Mechanical Engineers, New York, Paper 75 HT4.

Dayan, A. and Tien, C.L. (1974). Radiant Heating from a Cylindrical Fire Column, Combustion Science and Technology 9, 41.

Evans, D. (1985). To be published

Gunther, R., Horch, K. and Lenze, B. (1981). "The Stabilization Mechanism of Free Jet Diffusion Flames", Colloque International Berthelot-VieilleMallard-Le Chatelier, First Specialists Meeting (International) of the Combustion Institute, p. 117 .

Hottel, H.C. and Sarofim, A.F. (1967). Radiative Transfer, McGraw-Hill Book Company, New York, p. 232.

Jeng, S.M., Chen, L-D., and Faeth, G.M. (1982). "The Structure of Buoyant Methane and Propane Diffusion Flames, Nineteenth Symposium (International) on Combustion, The Combustion Institute, pp. 349-358.

Kalghatgi, G.T. (1981). Blow-Out Stability of Gaseous Jet Diffusion Flames. Part I: In Still Air. Combustion Science and Technology 26, 233; Part II: Effect of Cross Wind, ibid, p. 241; Part III: Effect of Burner Orientation to Wind Direction, ibid 28, 241 (1982).

Kalghati, G.T. (1984). Lift-Off Heights and Visible Lengths of Vertical Turbulent Jet Diffusion Flames in Still Air, paper presented at 9 th (Internationa1) Colloquium on Gas Dynamics of Explosions and Reactive Systems, Poitiers, France, July 4-8, 1983 (Combustion Science and Technology 41,17 ).

Lockwood, F.C. and Moneib, H.A. (1982). Fluctuating Temperature Measurements in Turbulent Jet Diffusion Flames, Combustion and Flame 47, 291.

McCaffrey, B.J. (1981). Some Measurements of the Radiative Power Output of Diffusion Flames, Paper No. WSS/CI 81-15, Western States Section, Combustion Institute, Pullman, WA. 
McCaffrey, B.J. (1983). Momentum Implications for Buoyant Diffusion Flames, Combustion and Flame 52, 149.

McCaffrey, B.J. (1984). Jet Diffusion Flame Suppression Using Water Sprays, Final Report, NBSIR 84-2812-1, U.S. Dept. of Commerce, Washington, DC, July 1985; also, Combustion Science and Technology 40, 107.

Peters, N. and Williams, F.A. (1983). Liftoff Characteristics of Turbulent Jet Diffusion Flames, AIAA J. 21, 423.

Ricou, F.P. and Spalding, D.B. (1961). Measurements of Entrainment by Axisymmetric Turbulent Jets, J. Fluid Mechanics 11, 21.

Santoro, R.J. (1986). Personal communication.

Schuller, R.B., Nylund, J., Sonju, O.K. and Hustad, J. (1983). Effect of Nozzle Geometry on Burning Subsonic Hydrocarbon Jets, in Fire Dynamics and Heat Transfer, The 21st National Heat Transfer Conf., Seattle, July 1983, p. 33.

Sonju, O.K. and Hustad, J. (1985). An Experimental Study of Turbulent Jet Diffusion Flames, in Dynamics of Flames and Reactive Systems, ed. Bowen, J.R., et al., Vol. 95, Progress in Astronautics and Aeronautics.

Sur1s, A.L., Flankin, E.V. and Shorin, S.N. (1977). Length of Free Diffusion Flames, Combustion Explosion and Shock Waves 13, 459.

Vanquickenborne, L. and van Tiggelen, A. (1966). The Stabilization Mechanism of Lifted Diffusion Flames, Combustion and Flame 10, 59. 
A

$\mathrm{c}_{2}$

$D_{f}$

D

$d_{b}$

de

$f(D)$

F

Fr

g

$\mathrm{H}_{f}$

$\mathrm{H}_{\mathrm{S}}$

$\Delta \mathrm{H}$

$k_{f}$

$\mathrm{L}_{\mathrm{f}}$

in

M

$\dot{q}^{\prime \prime}$

Q

$Q_{R A D}$

r

$\mathrm{R}_{\mathrm{H}}$

$\mathrm{S}_{\mathrm{u}}$

I

$\mathrm{T}_{\mathrm{f}}$

area ratio, $\mathrm{A}_{\mathrm{CH}_{4}} / \mathrm{A}_{\mathrm{H}_{2}} \mathrm{O}$

constant in Kalghatgi's lift-off correlation, Eq. (5)

flame diameter

burner diameter

burner diameter

effective burner diameter in chocked flow situations, Eq. (1)

flame geometric factor, e.g., mean beam length

radiative view factor

Froude number $\mathrm{U}^{2} / \mathrm{gD}$

gravitational acceleration

flame height

distance from burner exit where mean fuel concentration falls to stoichiometric level $\mathrm{H}_{\mathrm{s}}=\left[72.7\left(\mathrm{\rho}_{\mathrm{e}} / \rho_{\infty}\right)^{1 / 2}+5.8\right] \mathrm{d}_{\mathrm{e}}$ for a pure $\mathrm{CH}_{4}$ jet

$\mathrm{H}$ heat of combustion

extinction coefficient

lift-off height

mass flow rate

exit Mach number after expansion

incident radiant flux to a target

nominal heat release rate, net calorific potential of fuel

that portion of $Q$ radiated away

water to gas mass flow rate ratio

Reynolds number based on lift-off height $=\mathrm{S}_{u} \cdot \mathrm{H}_{\mathrm{s}} / \nu_{\mathrm{e}}$

maximum laminar flame speed $\left(0.39 \mathrm{~m} / \mathrm{s}\right.$ for $\left.\mathrm{CH}_{4}\right)$

temperature

flame temperature (radiation model) 


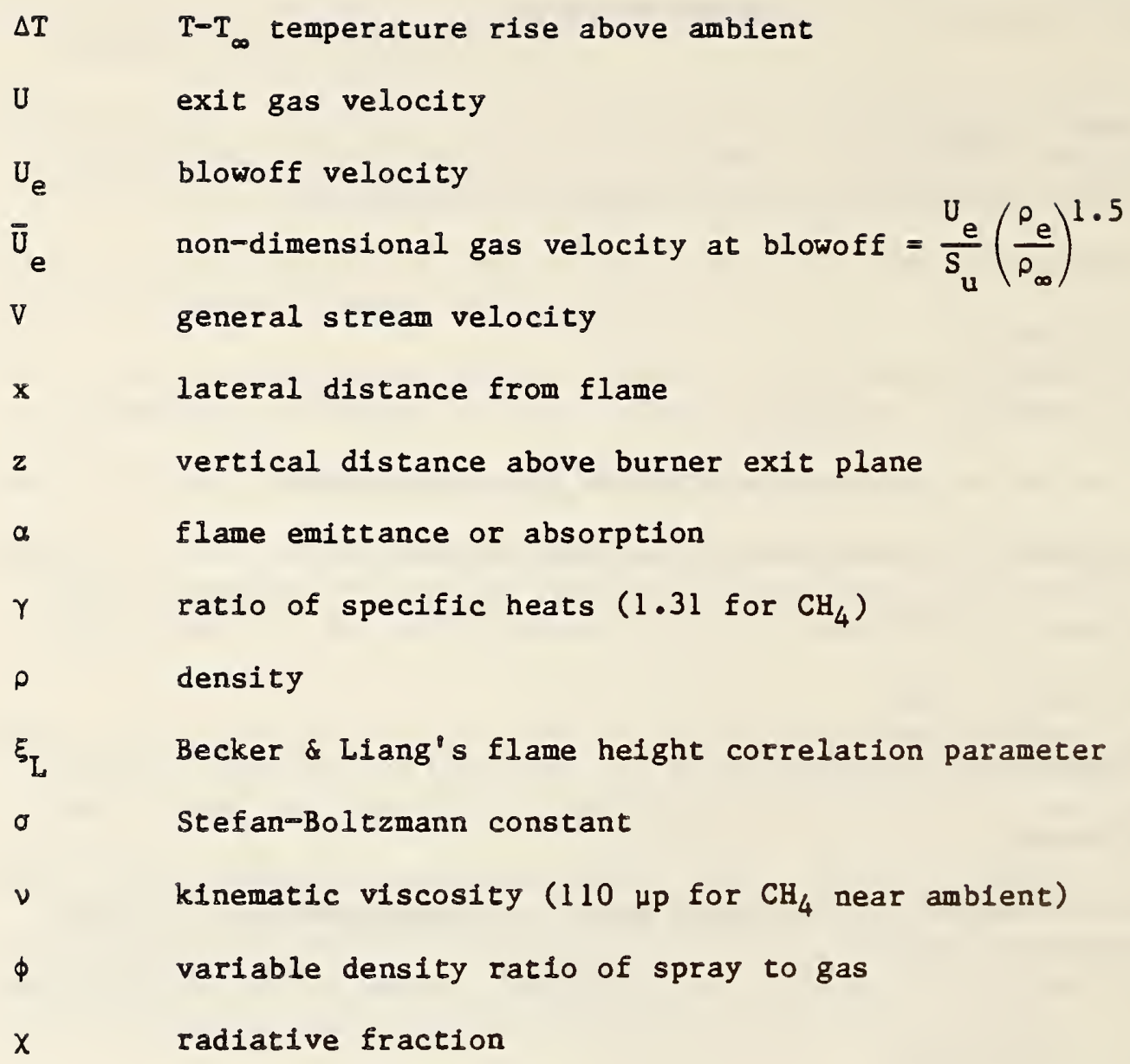

\section{Subscripts}

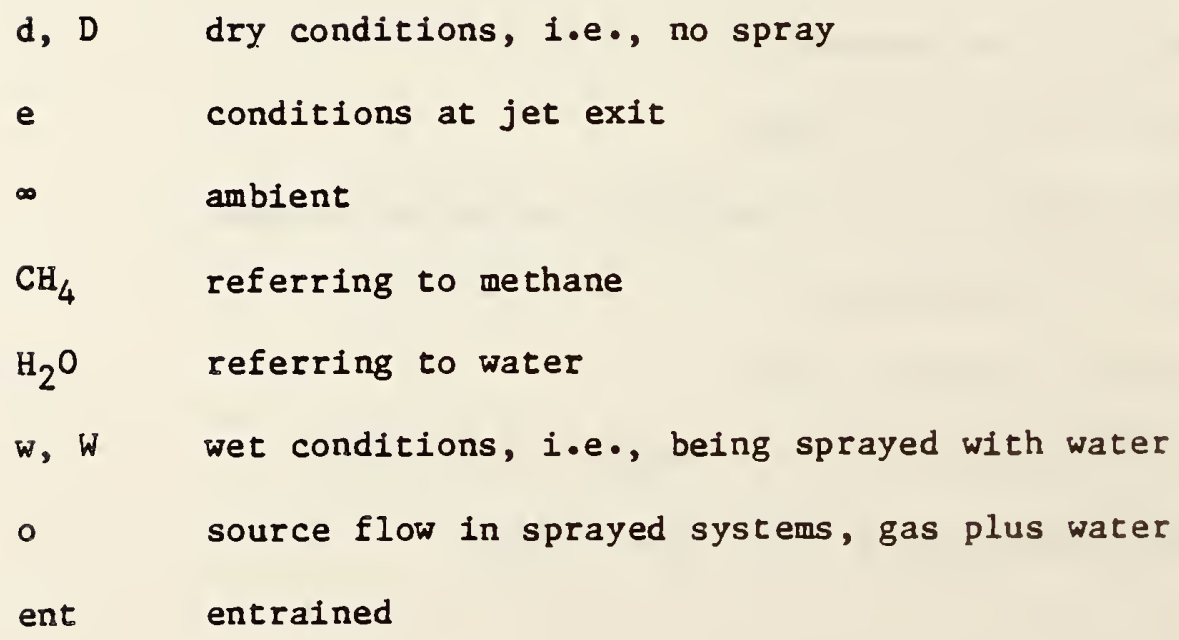



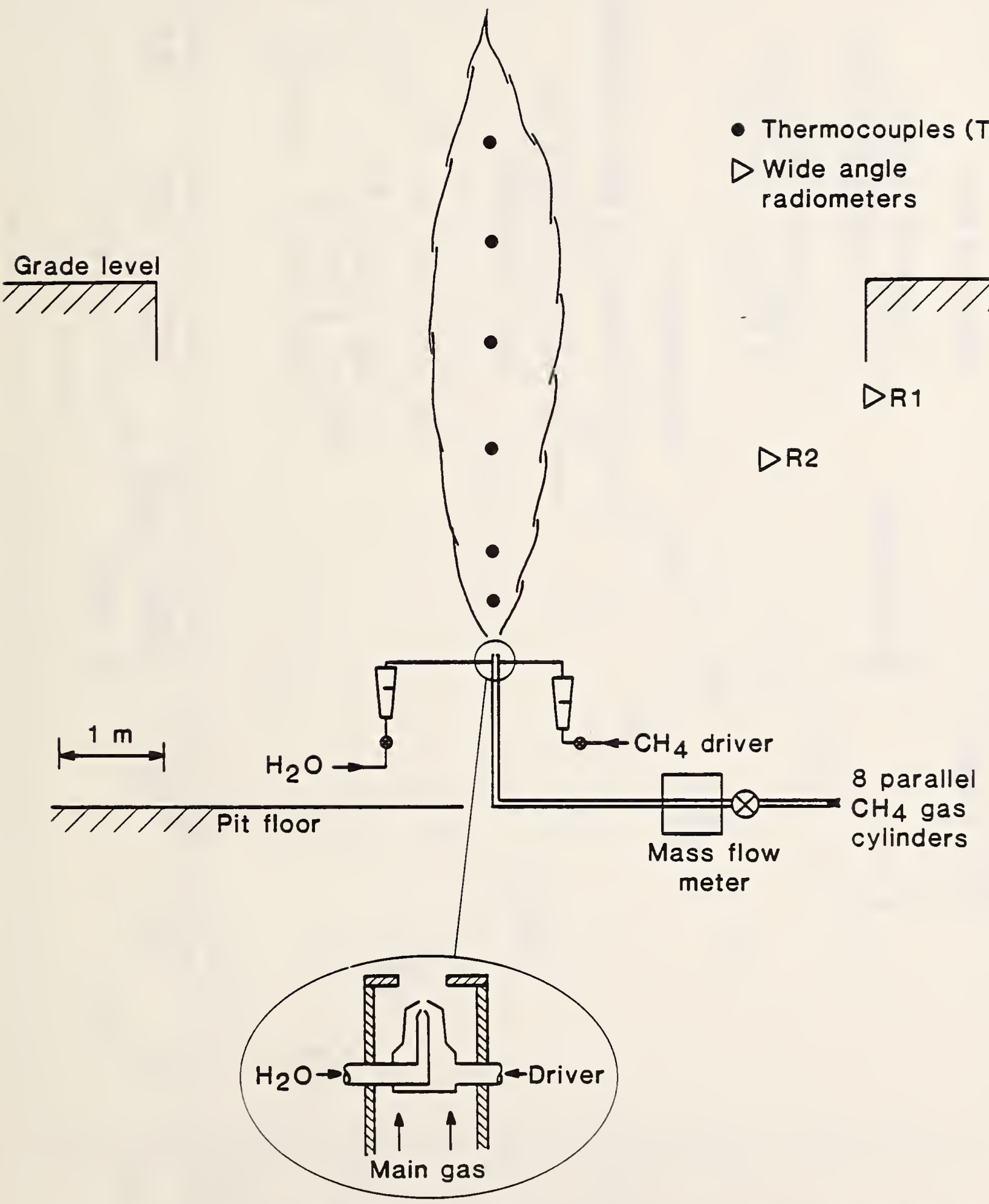

Plgure 1. Schematic of experimental facility 


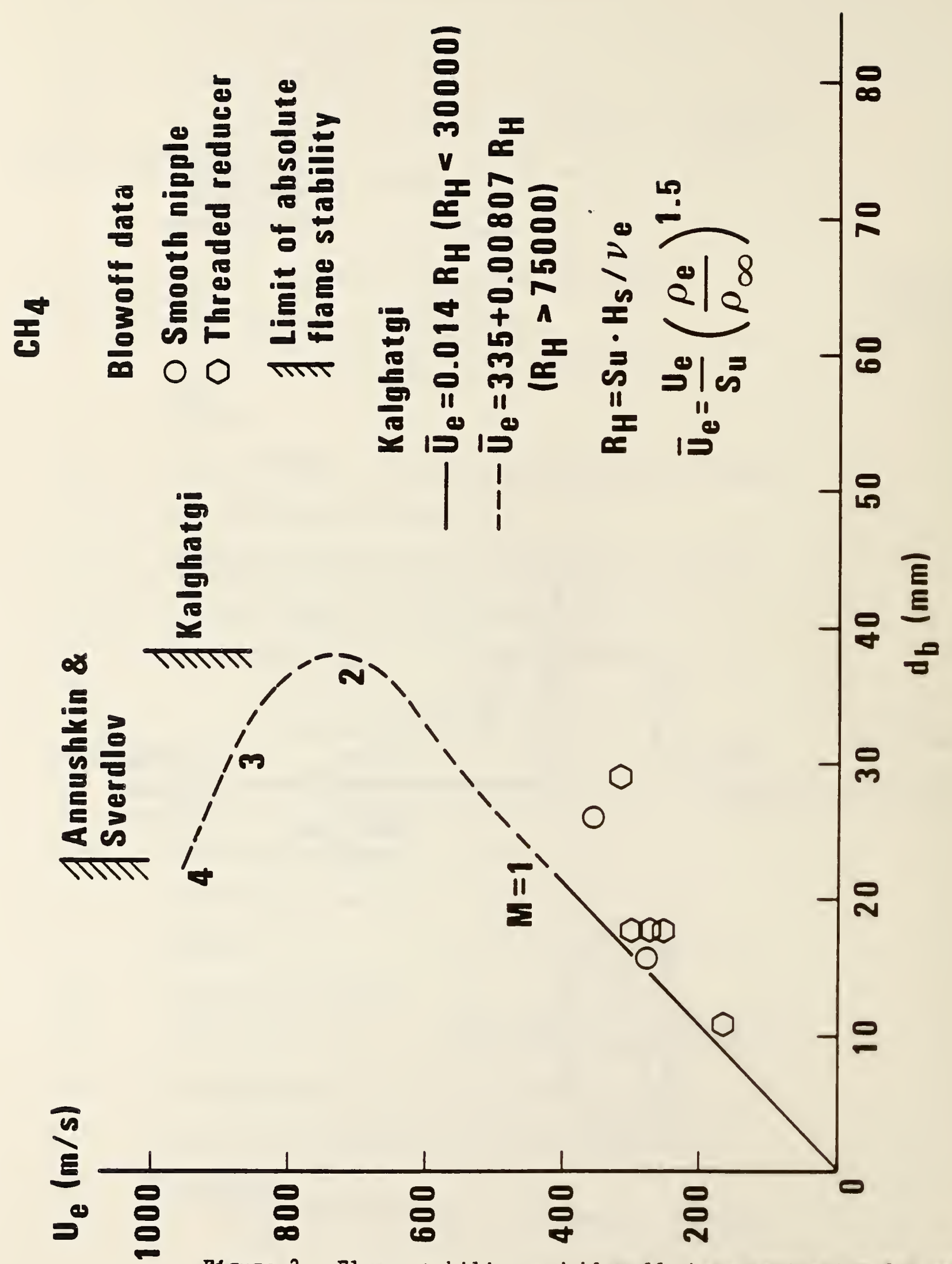

Plgure 2. Flame stabllity and blowof characterlzation for methane 


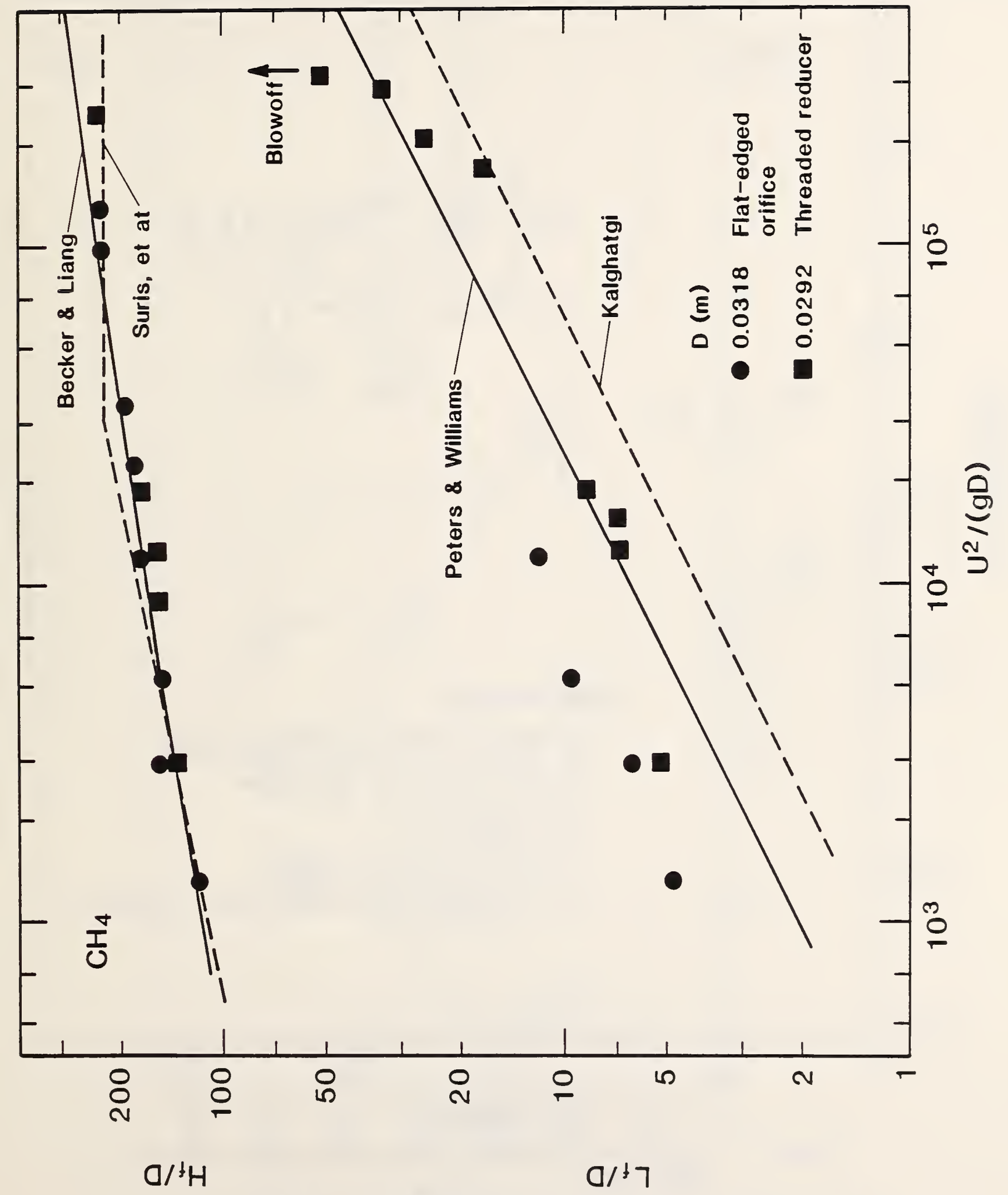

Plgure 3. Flame and 11ft-off heights vs Proude number 


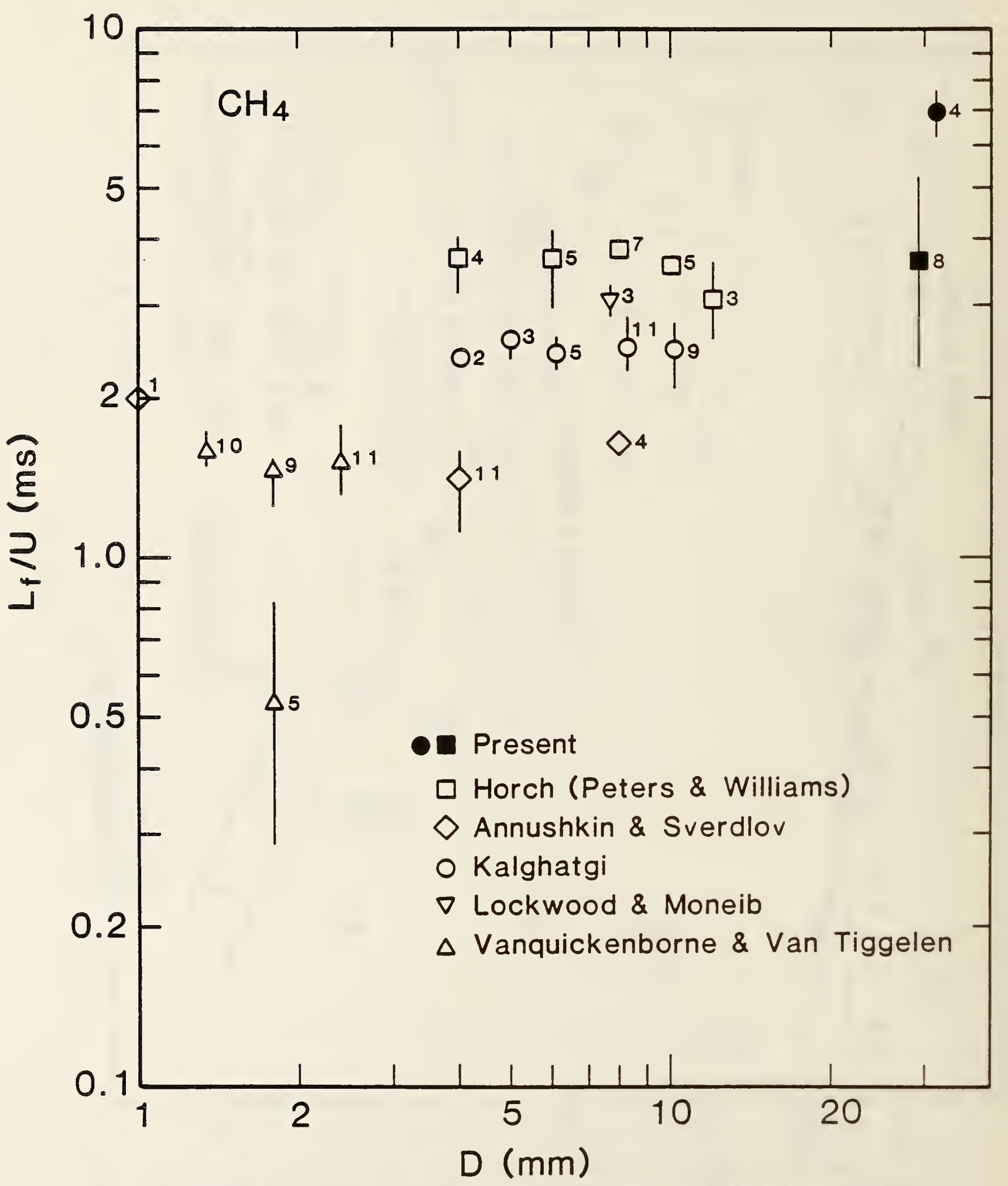

Figure 4. Present and literature summary of methane lift-off helght dara 


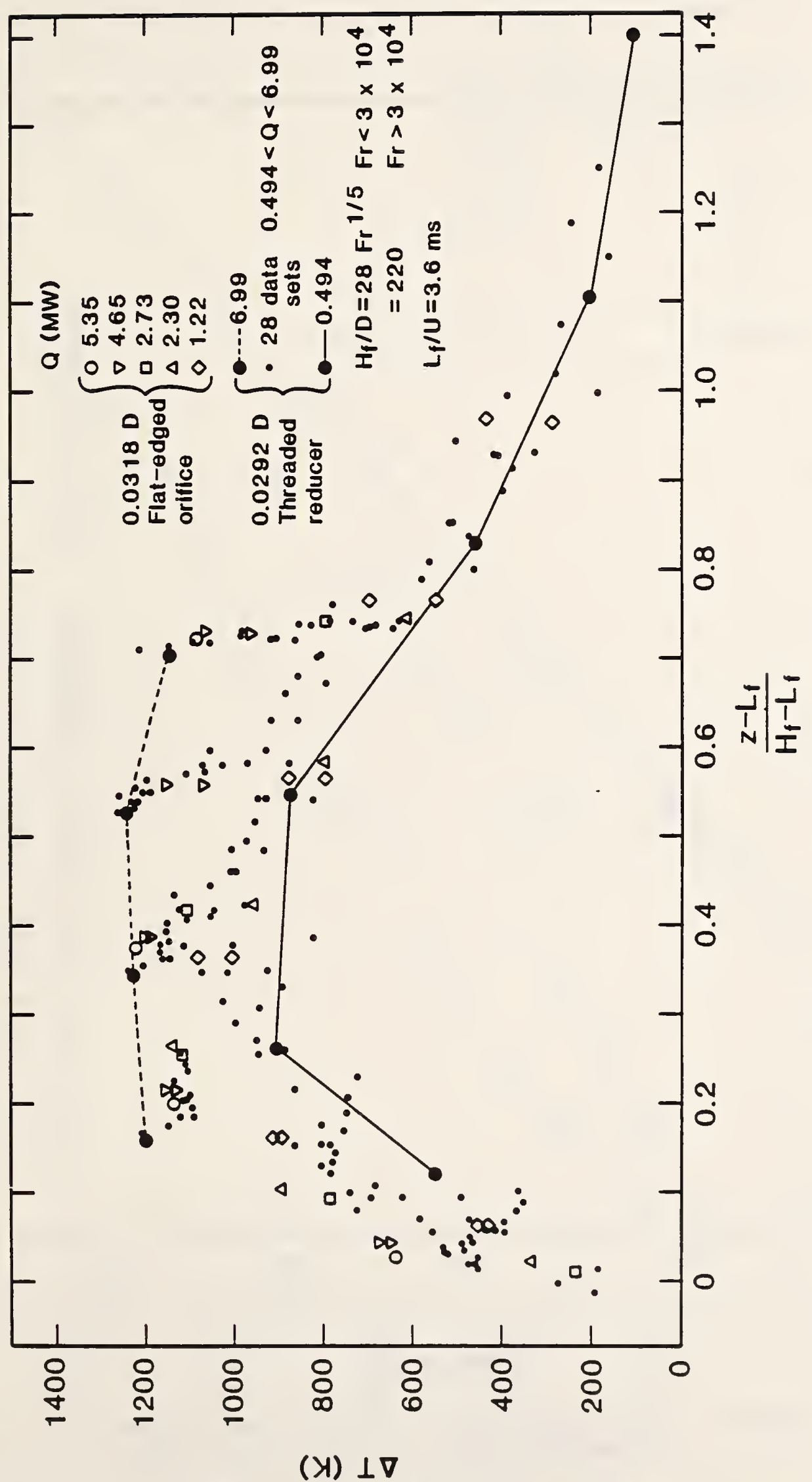

Plgure 5. Centerline temperature rise vs scaled helght 


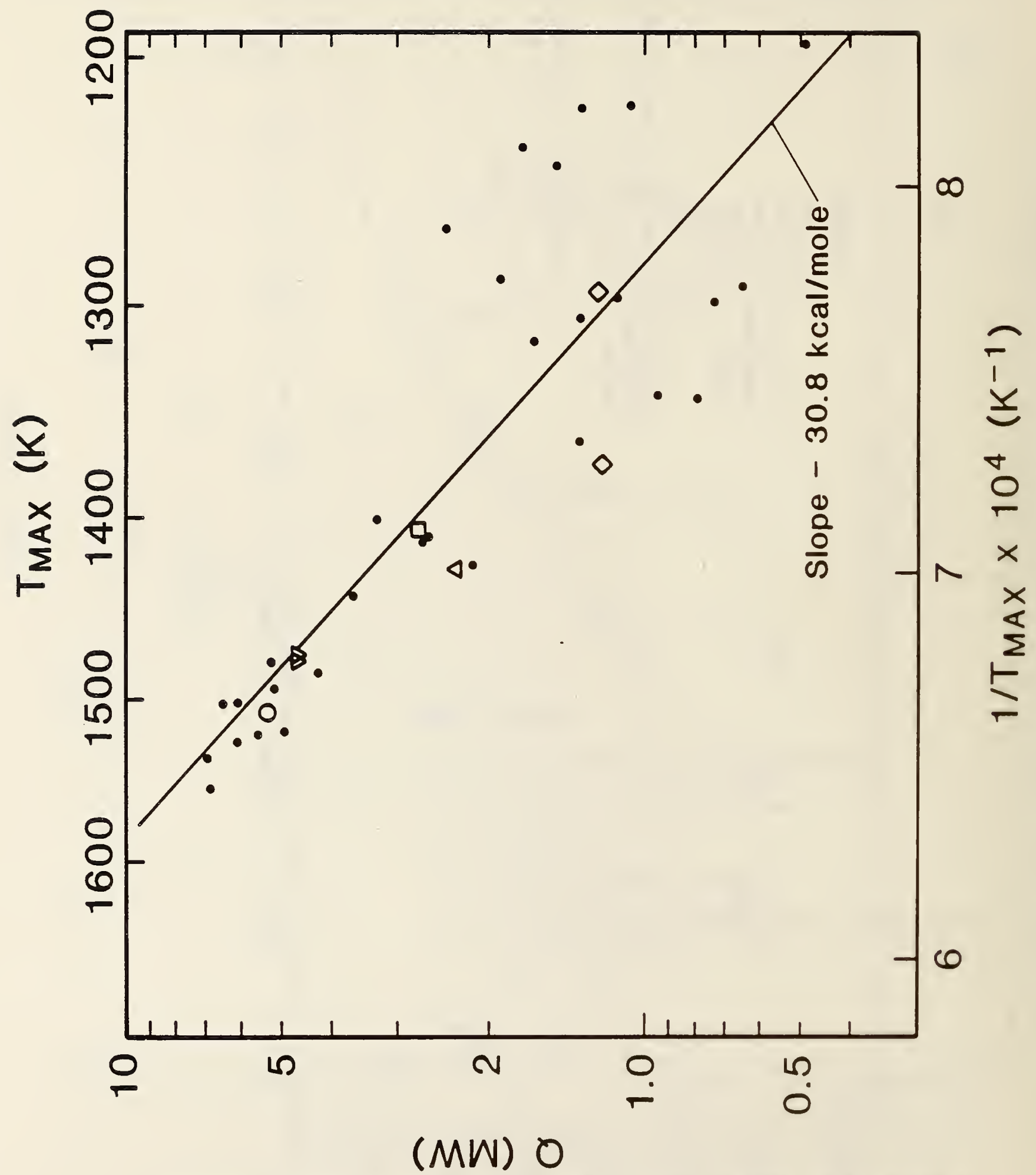

P1gure 6. Peak temperature vs nomlnal heat release rate (symbols follow P1g. 5) 


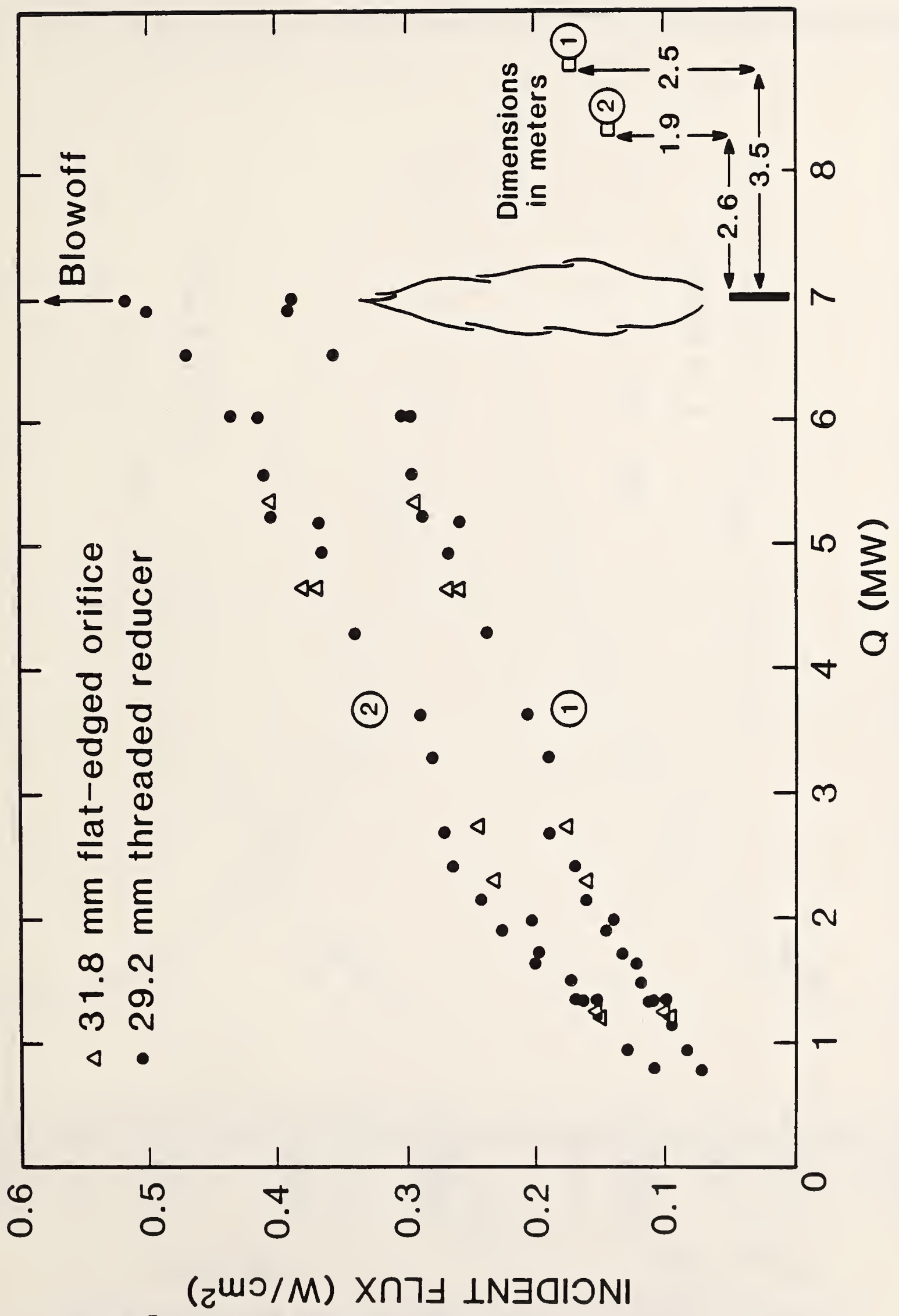

Figure 7. Incldent radiant flux to two targets as a function of fire size 


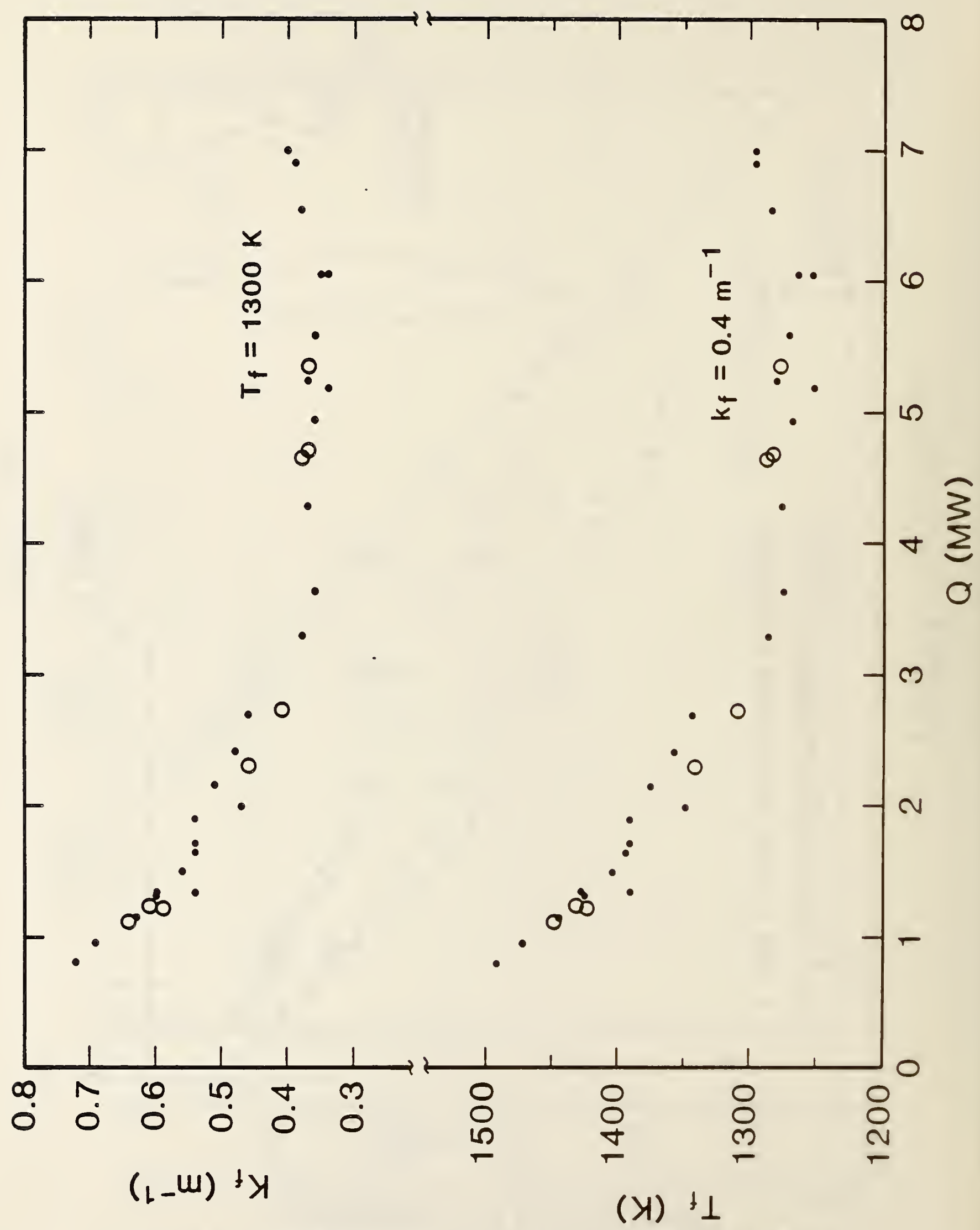

Figure 8. Flame extinction coefficlent and temperature for a fixed value of the other as a function of fire size 


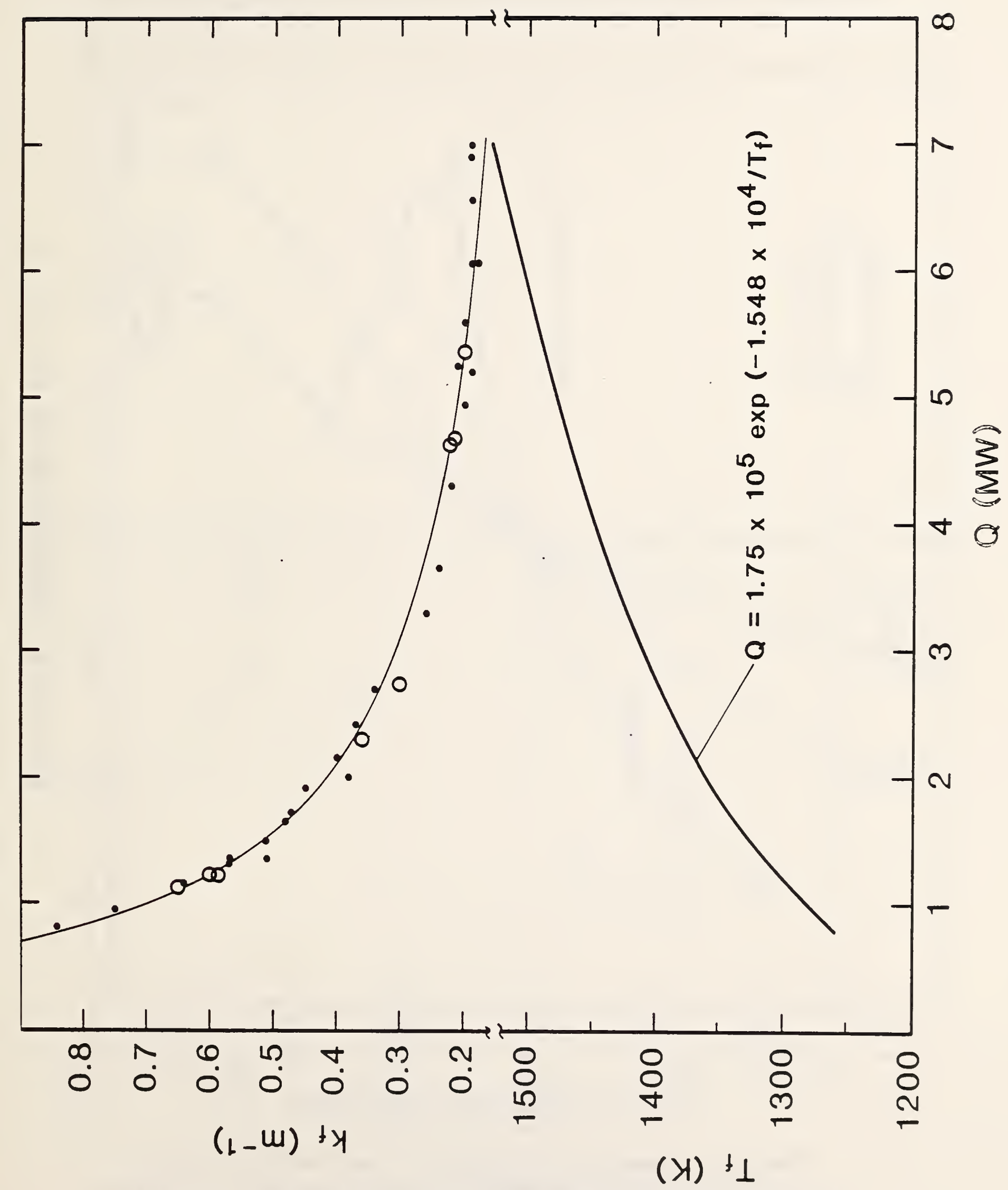

Figure 9. Derived extinction coefficient (upper portion) using smoothed temperature data from FIg. 6 (lower portion) vs heat release rate 55 


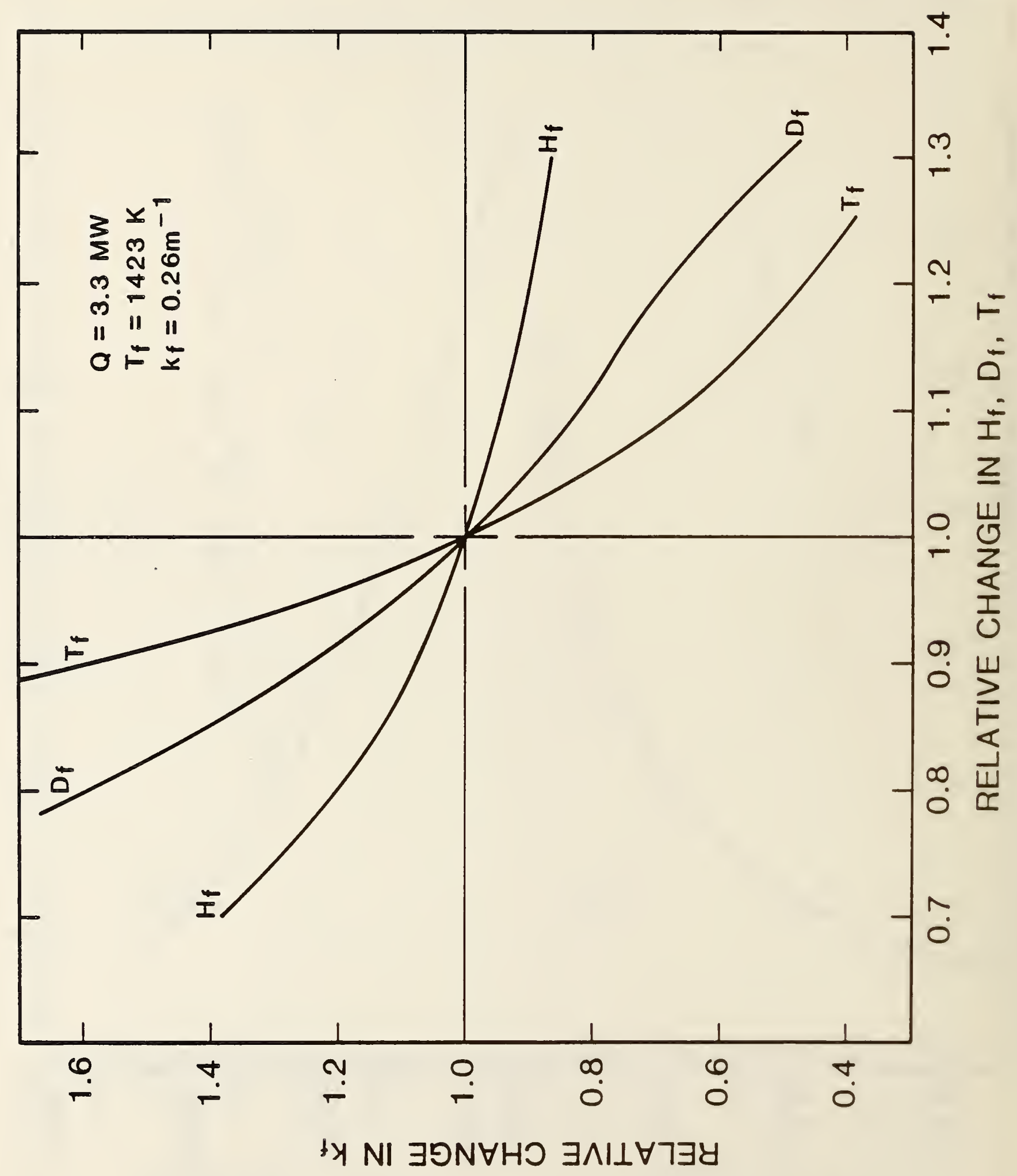

Figure 10. Sensitivity analysis of flame radiation model to varlous parameters 


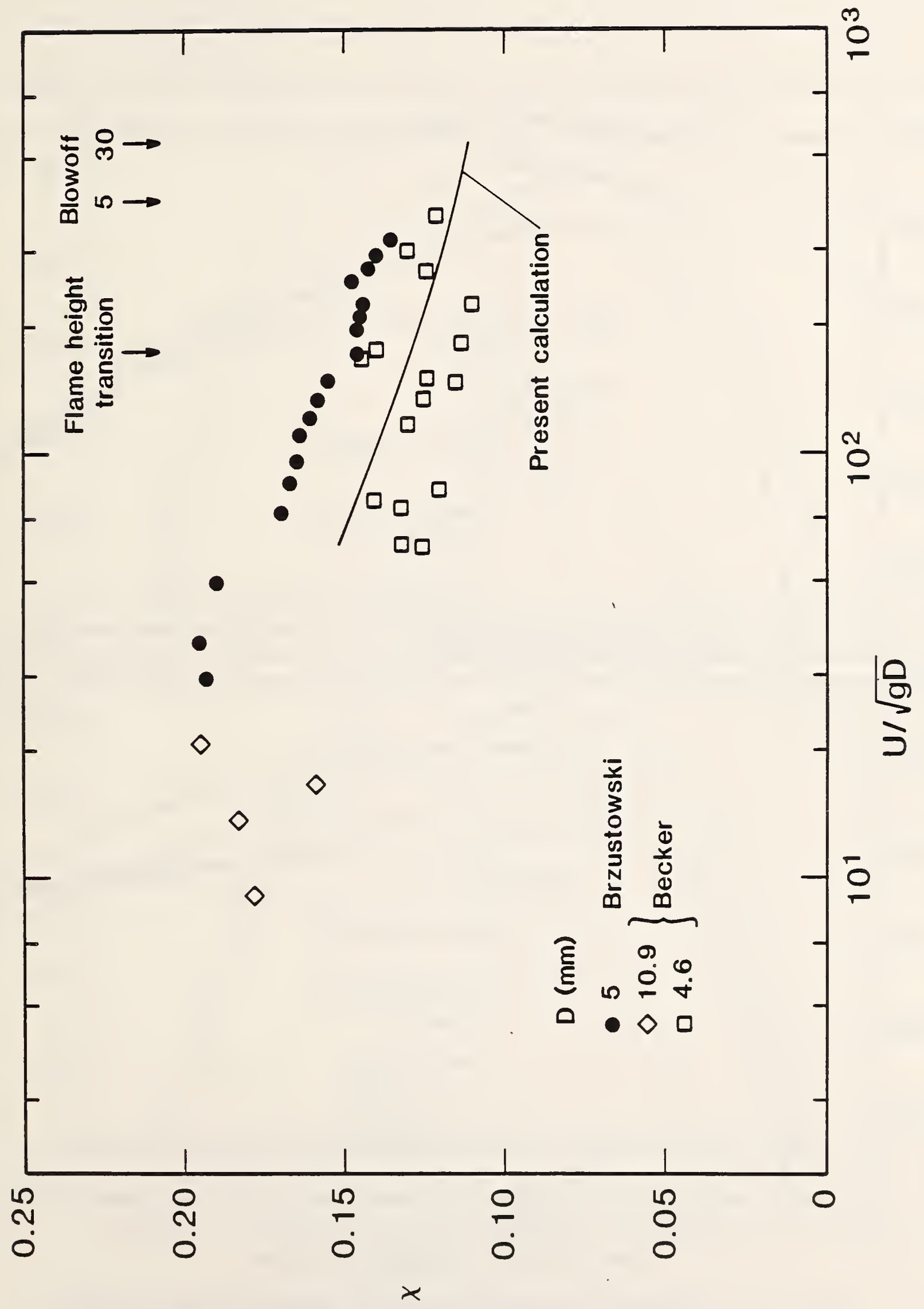

F1gure 11. Predicted decreasing radiative fraction compared to literature data plotted as a function of the square root of Proude number 


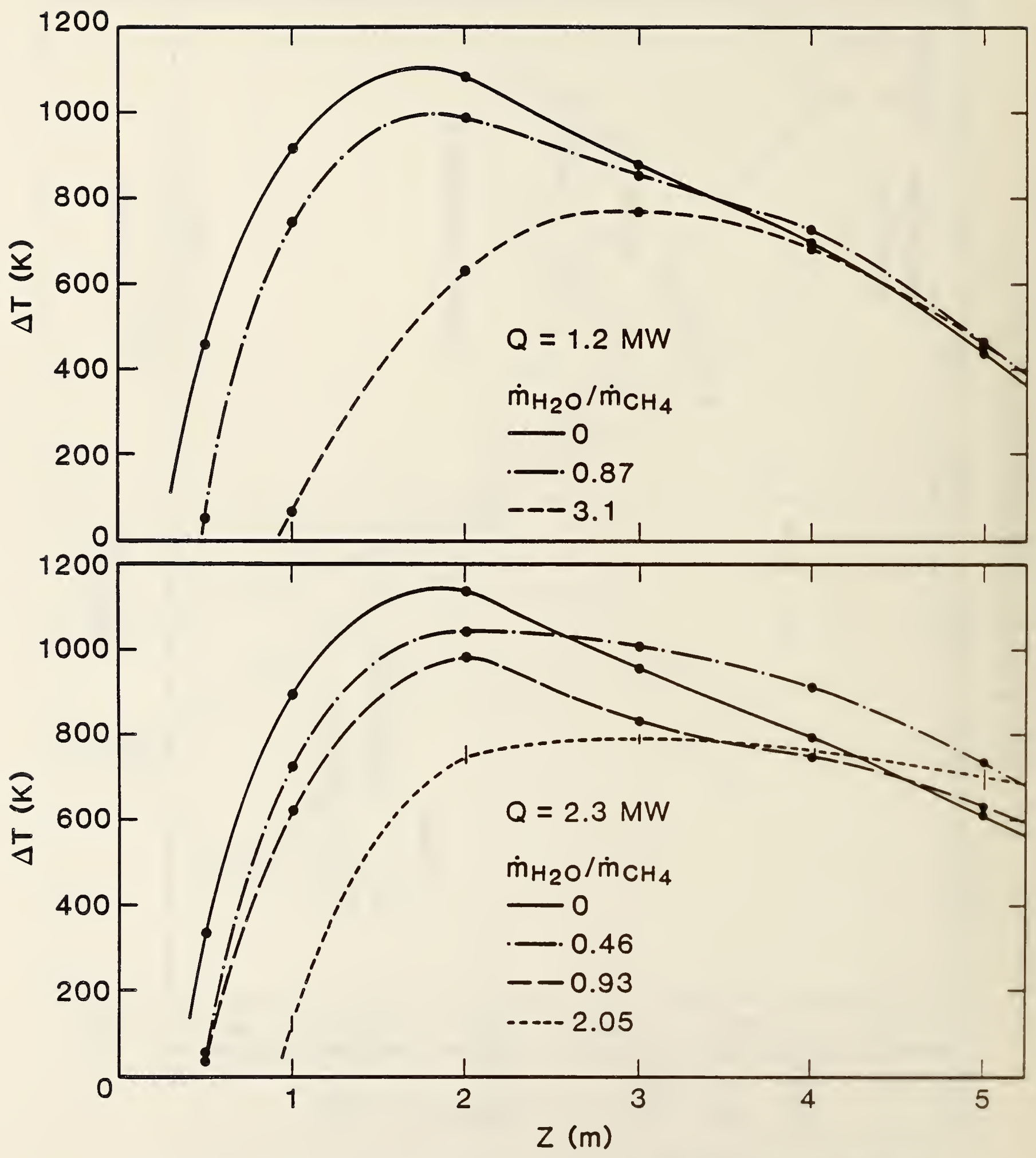

Figure 12. Centerline temperature rise vs height with and without water $\operatorname{spray}(Q=1.2$ and $2.3 \mathrm{MW})$ 


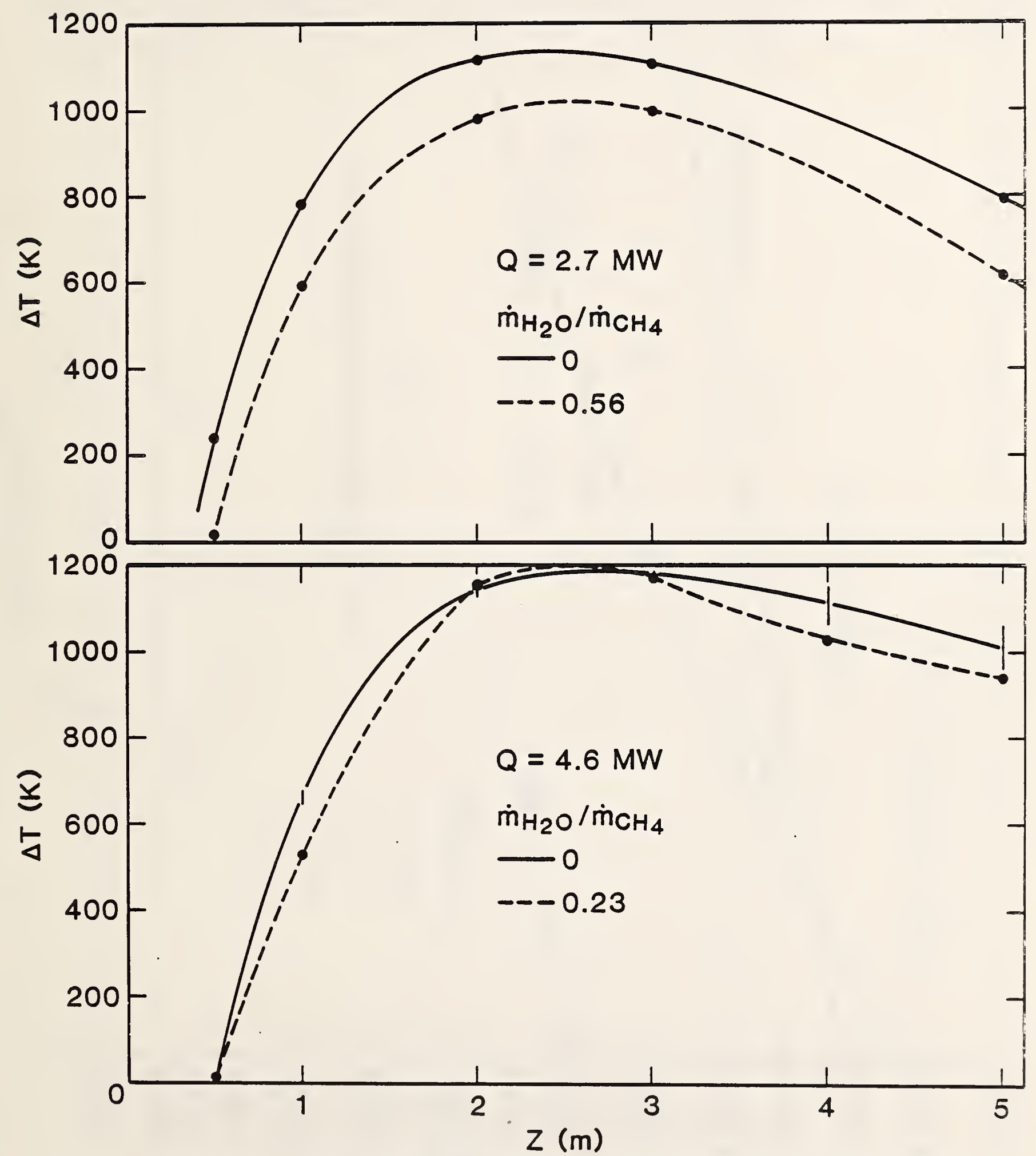

Figure 13. Centerline temperature rise vs height with and without water spray $(Q=2.7$ and $4.6 \mathrm{MW})$ 


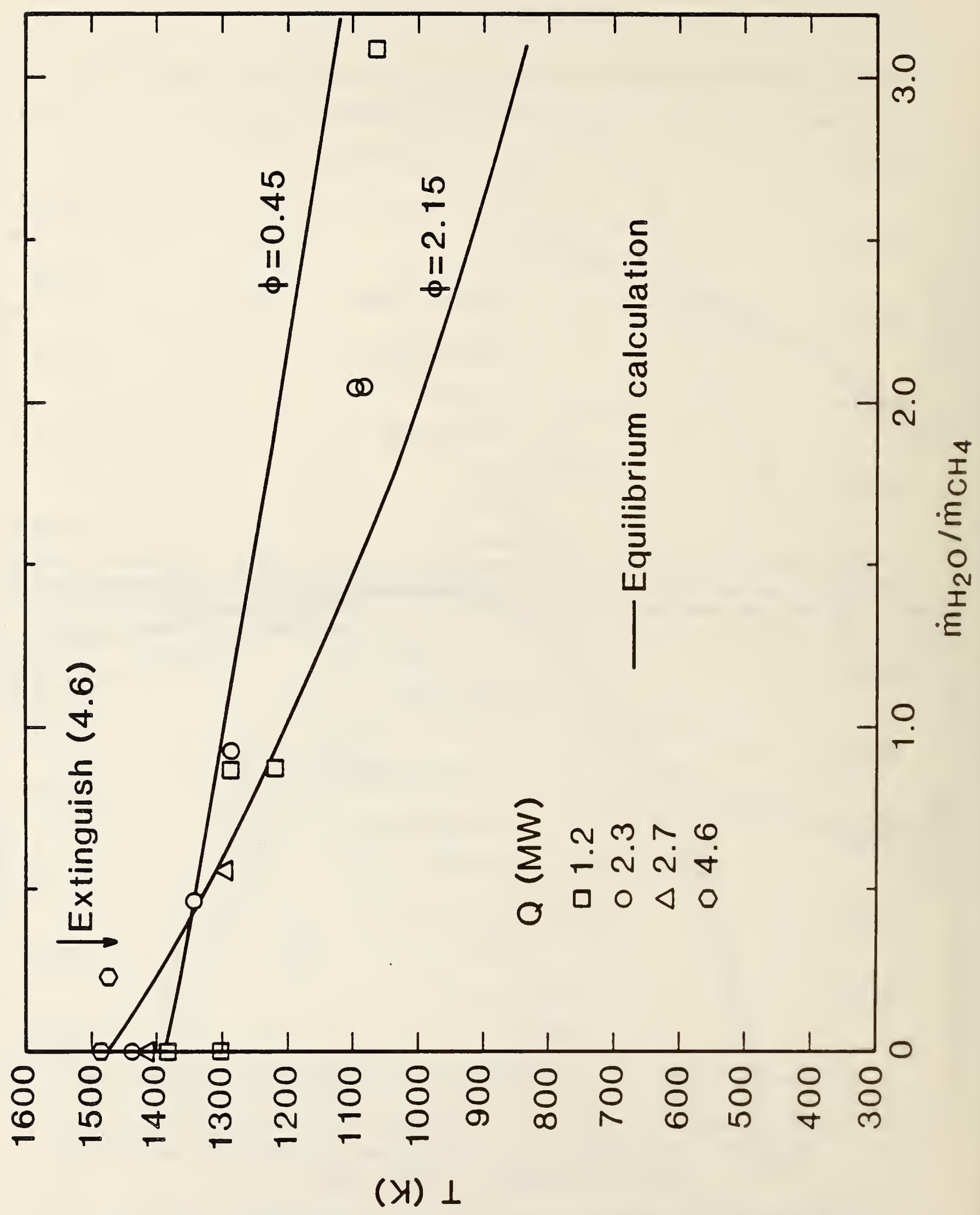

Figure 14. Reduction of peak temperature with water flow rate 


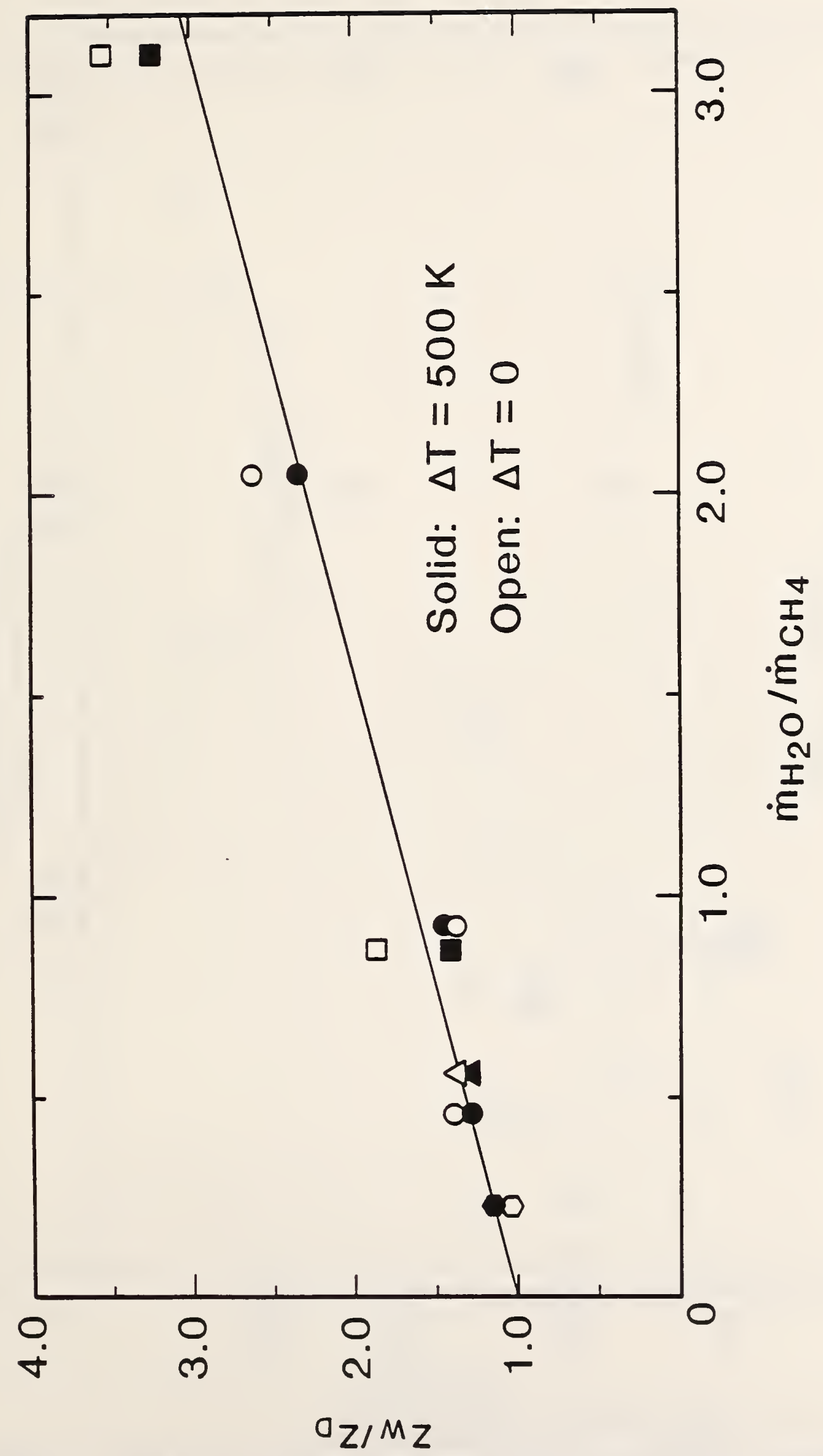

Pigure 15. Practional increase in lift-off helght due to water spray as a function of mass flow ratio 


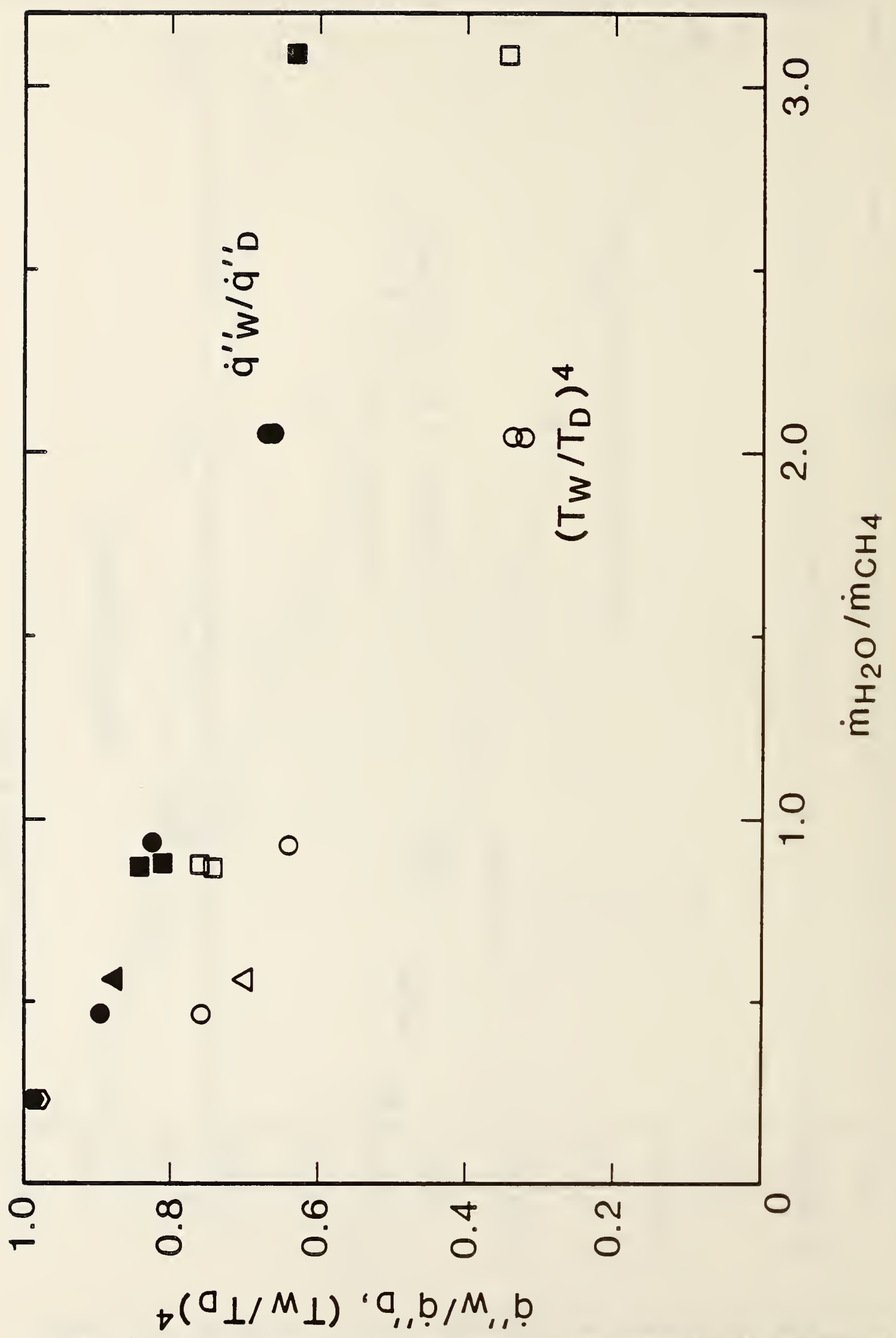

Pigure 16. Normalized incident flux and flame temperature reductions vs $\dot{\mathrm{m}}_{2} \mathrm{O}^{/ \dot{\mathrm{m}}_{\mathrm{CH}}}$ 


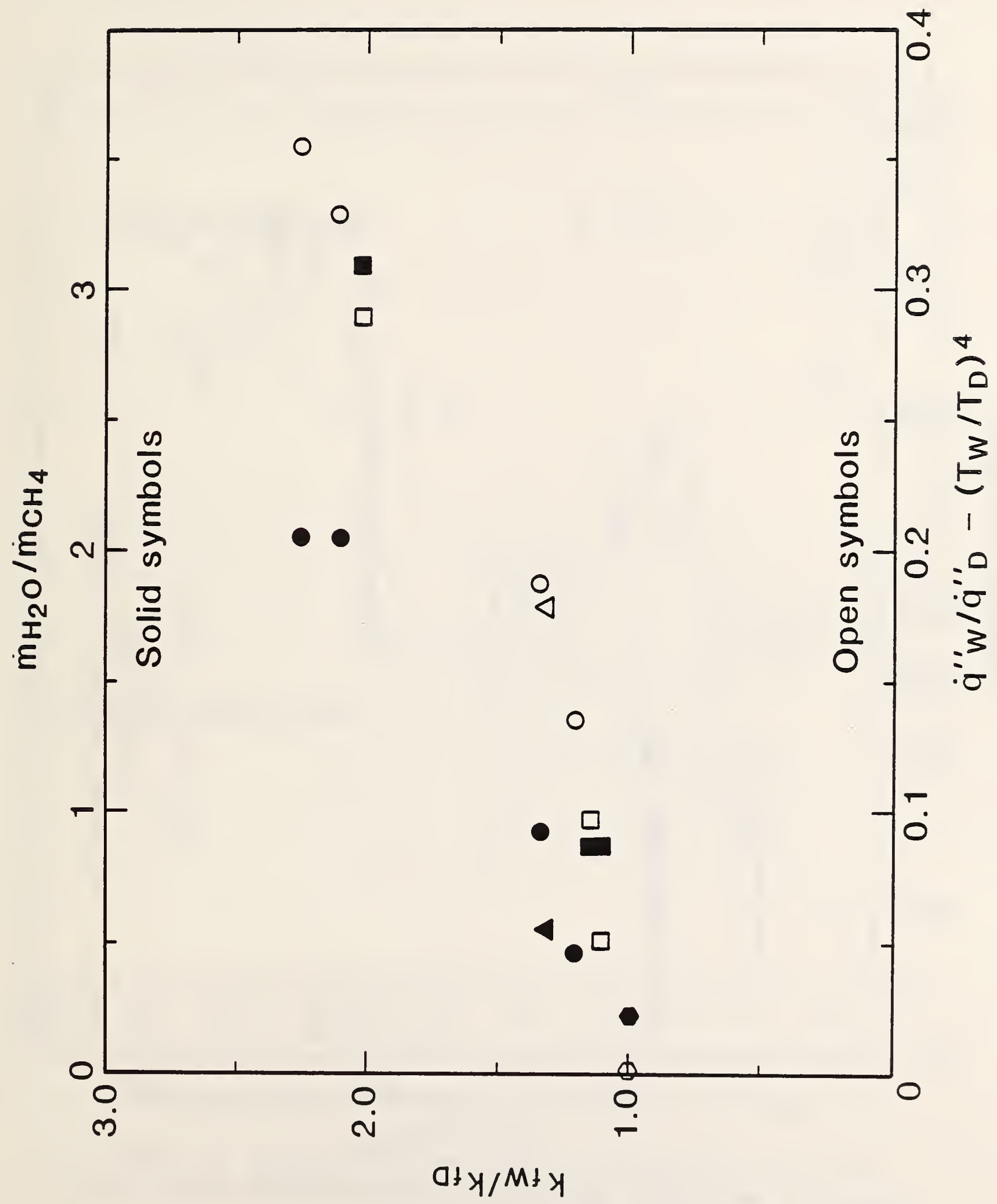

Figure 17. Increase in flame absorptivity as a function of both water flow rate and the difference between the heat flux and $\frac{7}{1}$ readings 


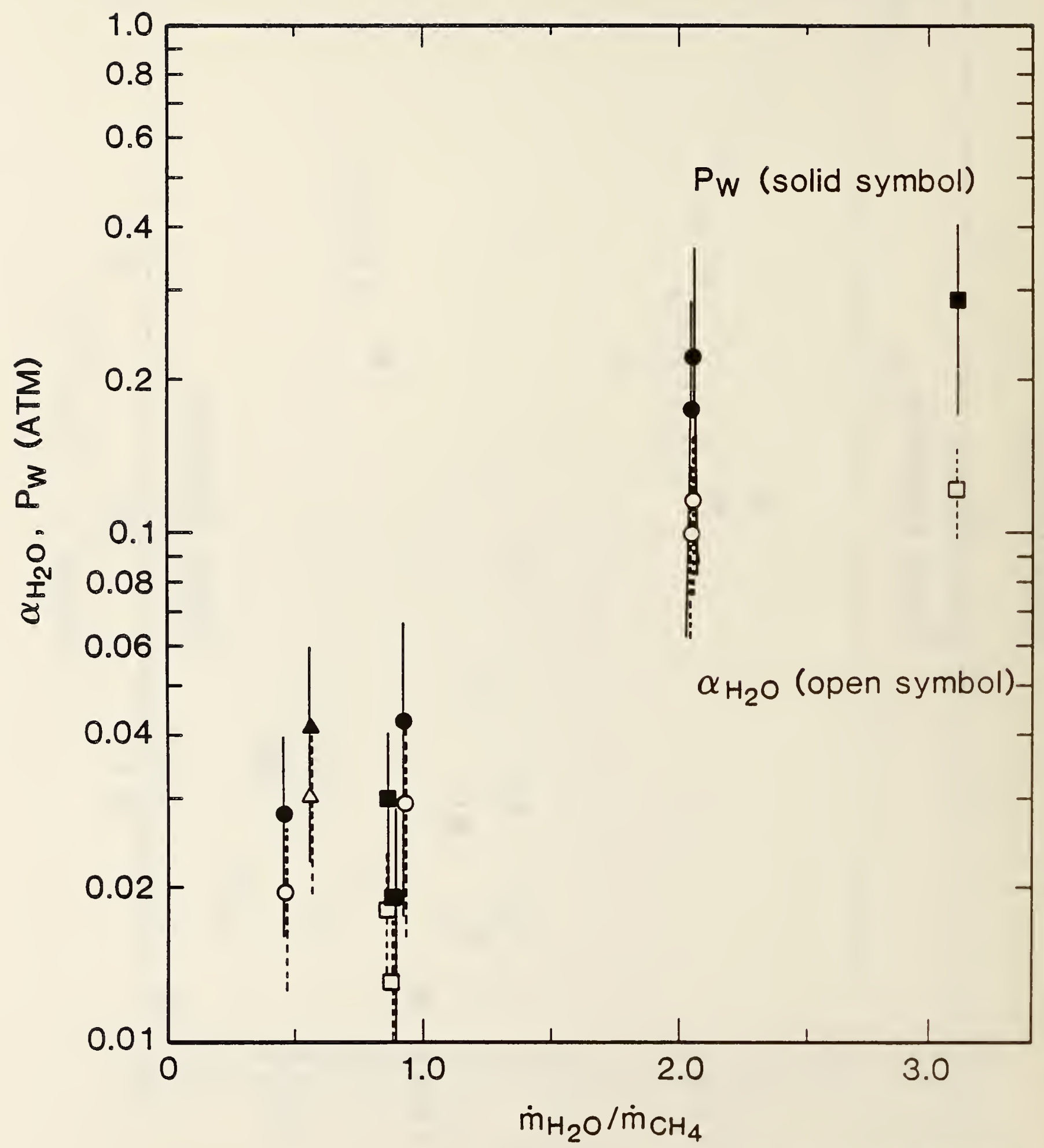

Figure 18. Water vapor emlssivity and partial pressure plotted agalnst the water to gas flow ratio 


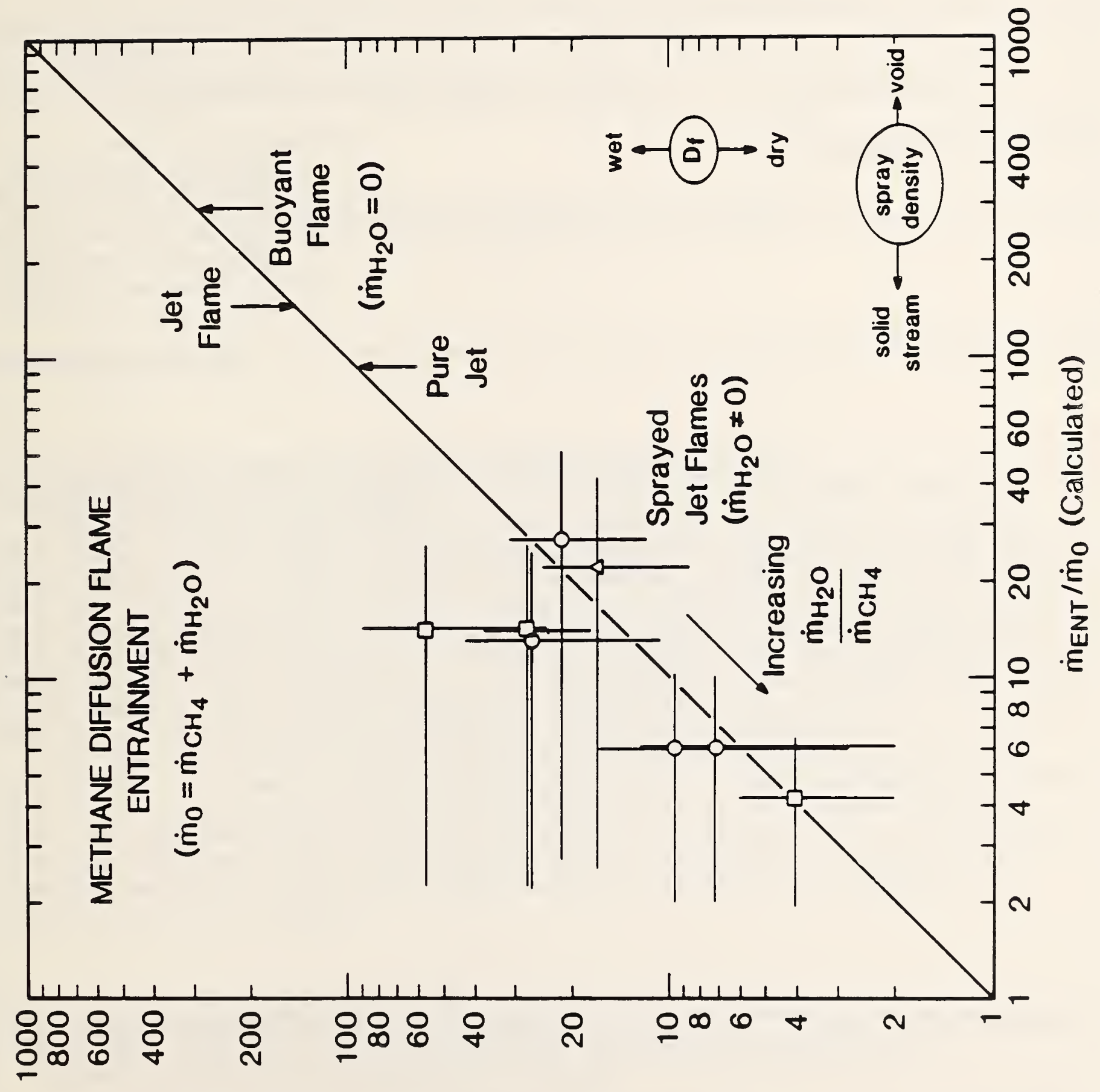

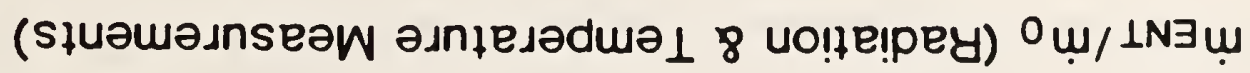

F1gure 19. Derlved entralnment rates vs predictlons of $R A c o u$ and Spalding (1961) using effective source oV 

DS-1 I AA (REV. 2-8C)

U.S. DEPT. OF COMM.

BIBLIOGRAPHIC DATA

SHEET (See in struction S)

1. PUBLICATION OR
REPORT NO.
NBSIR-86/3442

2. Performing Organ. Report No.

3. Publication Date

November 1986

4. TITLE AND SUBTITLE

Momentum Diffusion Flame Characteristics and the Effects of Water Spray

5. AUTHOR(S)

B. J. McCaffrey

6. PERFORMING ORGANIZATION (If joint or other thon NBS, see instructions)

7. Contracd Grant No.

National Bureau of Standards

Department of Commerce

Gaithersburg, MD 20899

9. SPONSORING ORGANIZATION NAME AND COMPLETE ADDRESS (Street, City, Stote, ZIP)

Department of Interior

Minerals Management Service

Reston, VA

10. SUPPLEMENTARY NOTES

Document describes a computer program: SF-185. FIPS Software Summary, is attached.

11. ABSTRACT (A 200-word or less factual summary of most significant information. If document includes a significant bibliogrophy or literoture survey. mention it here)

For water spray suppression of gas well blowout fire applications, reasonably

large scale (1-10 MW) methane diffusion flames have been investigated near the high

Froude number limit. Flame blow-off has been observed with pipe sizes to $30 \mathrm{~mm}$ diameter. Flame and lift-off heights, centerline temperatures and incident radiative flux to nearby targets have been measured with and without water spray suppressant. Using the Dayan-Tien formulation for a cylindrical flame model an effective gray absorption coefficient approaching $0.2 \mathrm{~m}^{-1}$ was determined at the blow-off limit. The derived shape of the functional dependence of decreasing radiative fraction with jet Froude number in the limit is consistent with smal1 scale experiments.

The effect of spraying water internal to the flame envelope at the base is to shift or raise the flame above its normal position and to lower peak flame temperature and radiation levels despite increased absorptivity due to the radiatively active steam. Extinguishment near blowoff is thought due to te former effect. Calculations of flame entrain.ment based on increased water vapor emission are consistent with literature estimates of entrainment when account of the effects of buoyancy due to the liquid spray is provided.

12. KEY WORDS (Six to twelve entries: alphobetical order: copitalize only proper names; and seporate key words by semicolons) blow-off, blowout fires, diffusion flames, entrainment, extinguishment, radiative fraction, suppression, water sprays

13. AVAILABILITY

Xxx Unlimited

14. NO. OF

PRINTED PAGES

For Official Distribution. Do Not Release to NTIS

$\square$ Order From Superintendent of Documents, U.S. Government Printing Office, Washington, D.C. 20402.

X] Order From National Technical Information Service (NTIS), Springfield, VA. 2216I 


